\title{
Evaluation of Imam Khomeini Hospital of Tehran Compliance with the Standards of Patient Safety Friendly Hospital about the COVID-19 Pandemic: A Case Report
}

\author{
Maryam Farahani ${ }^{1}$, Maryam Esmaeili ${ }^{2}$, Hadis Ashrafizadeh $^{3}$, Fatemeh Hajibabaee ${ }^{4}$, \\ Shima Haghani ${ }^{5}$, Parasto Ariyamloo ${ }^{6}$
}

\begin{abstract}
Background \& Aims: Ensuring patient safety is the first vital step in improving the quality of healthcare services. Patient safety is defined as an event that prevents unwanted injuries to a patient due to functional and unintentional actions. Safety standards are a set of requirements that are critical to implementing patient safety programs at hospitals. These standards provide an operational framework to help the hospitals fully match with the dimensions of patient safety in order to provide quality and patient-centered services. Therefore, $100 \%$ compliance with the required standards of patient safety-friendly hospital should be the priority of every hospital. The COVID-19 pandemic is one of the emerging infectious diseases that has affected the whole world in recent months. As its outbreak is an unexpected event or sequence of events of enormous scale and overwhelming speed, it has led to a high degree of uncertainty and has posed a variety of challenges to healthcare systems. Therefore, the realization of this important issue is felt more than ever in the structures and processes of each hospital of the healthcare system, in order to successfully control and efficiently manage this disease and preserve national assets. Therefore, this study aimed to determine the compliance of Imam Khomeini Hospital of Tehran with the patient safetyfriendly hospital standards with respect to COVID-19 pandemic in 2020.

Materials \& Methods: This descriptive-analytical cross-sectional study was conducted from SeptemberDecember 2020 in Imam Khomeini Hospital Complex of Tehran during COVID-19 pandemic. 266 nurses with inclusion criteria were selected via stratified random sampling. For this purpose, the required list of 1,200 nurses was received from the nursing office of the complex. 866 nurses from 50 different wards were selected from the list based on the inclusion criteria. Then, the nurses who were in the same wards were placed in one stratum, so that the existing 50 wards including emergency department, operating room, ICU, CCU, NICU, dialysis, internal ward, surgical ward, infectious disease wards, oncology, pediatric ward, VIP and diagnostic wards were finally placed in 13 strata. Therefore, 292 samples were selected based on the quota of nurses from 13 existing strata via simple random sampling to provide a specified sample size of 266 nurses with an additional $10 \%$ to manage their attrition. Online sampling was performed by sending the link of the questionnaires through the virtual network of the study. The questionnaires included nurses' demographic information and patient safety-friendly hospital standards (Parvizi et al), including 27 items and five dimensions. The minimum score was 27 and the maximum score was 135. A higher score from the point of view of the research unit meant that the hospital was more in line with the standards of a patient safety-friendly hospital. Item 21 was scored in reverse. Scores 108-135 showed high compliance, scores 80-107 indicated moderate compliance, and scores 27-79 indicated the poor compliance of the hospital with the standards of patient safety friendly hospital. The internal consistency of the instrument

\footnotetext{
1. Management and Intensive Care Department, School of Nursing and Midwifery, Tehran University of Medical Sciences, Tehran, Iran

2. Management and Intensive Care and Department, School of Nursing and Midwifery, Tehran University of Medical Sciences, Tehran, Iran

3. Student Research Committee, School of Nursing and Midwifery, Ahvaz Jundishapur University of Medical Sciences, Ahvaz, Iran

${ }^{4}$. Intensive Care and Management Department School of Nursing and Midwifery, Tehran University of Medical Sciences, Tehran, Iran (Corresponding author) Tel: 09188141451 Email: f-hajibabaee@sina.tums.ac.ir

5. Biostatistics, Nursing Care Research Center, Iran University of Medical Sciences, Tehran, Iran

${ }^{6}$. Nursing Managemant, Imam Khomeini Hospital, Tehran University of Medical Sciences, Tehran, Iran
} 
was determined to be 0.934 using Cronbach's alpha. After introducing the researcher and explaining the research objectives to the research units, data were collected. Data were analyzed using descriptive statistics including absolute and relative frequency distribution, mean and standard deviation in SPSS software version 16.

Results: The mean and standard deviation of the age of nurses was $38.6 \pm 7.94$ years and most of them $(90.2 \%)$ were female. The mean and standard deviation of the total length of service as a nurse and the length of service in the current ward was $13.87 \pm 7.41$ and $6.87 \pm 5.80$ years, respectively. ICU nurses had the highest frequency, $25.6 \%$, compared to other hospital wards, and also rotating shifts with $42.4 \%$ had the highest frequency. The level of compliance with the standards of patient safety friendly hospitals was $97.35 \pm 16.59$ from the perspective of most nurses (61.7\%) (80-107), and $3.58 \pm 0.62$ based on a Likert scale, which indicates moderate compliance. Continuing education dimension with the average compliance equal to $3.87 \pm 0.69$ had the highest mean and governance and leadership with the average compliance equal to $3.41 \pm 0.71$ had the lowest mean scores. Mean scores of dimensions of a safe environment, participation, and interaction with patients and the community, safe clinical services were $3.45 \pm 0.67,3.44 \pm 0.85$, and $3.71 \pm 0.7$, respectively.

Conclusion: Based on the findings of the present study, the level of compliance with the standards of a patient safety-friendly hospital was moderate in the Imam Khomeini Hospital complex during the coronavirus pandemic. The highest and lowest levels of compliance were related to the dimension of continuing education and the dimension of governance and leadership included in the standards of patient safety-friendly hospital. To improve the current situation, purposeful and evidence-based management of organizational resources, attention to "barriers to achievement" dimensions of patient safety, institutionalizing patient safety culture and promoting safety, attention and focus on patient safety indicators, continuous and effective training of educational staff needs are needed to improve the safety of beneficiaries, especially during the COVID-19 pandemic. Relying on the results of the present study, managers can take appropriate corrective measures to achieve $100 \%$ compliance with patient safety-friendly hospital standards and national accreditation standards, and achieve patient safety goals and provide quality and patient-centered services in the healthcare system. The results of the present study can provide a basis for examining the patient safety status and monitoring it in future researches. It is recommended that future researchers, in order to ensure patient safety and monitor the quality of healthcare and patient-centered services, analyze non-compliance in mandatory, basic, and advanced standards of patient safety-friendly hospitals using PSFHI checklist of the World Health Organization through the process of observation, interview, and review of documents in the Imam Khomeini Hospital complex.

Keywords: Standard, Patient Safety Friendly Hospital, Nurse, Patient safety, COVID-19, Pandemic.

\section{Conflict of Interest: No}

How to Cite: Farahani M, Esmaeili M, Ashrafizadeh H, Hajibabaee F, Haghani SH, Ariyamloo P. Evaluation of Imam Khomeini Hospital of Tehran Compliance with the Standards of Patient Safety Friendly Hospital about the COVID-19 Pandemic: A Case Report. Iran Journal of Nursing. 2021; 34(129): 50-66.

Received: 11 Jan 2021

Accepted: 12 Apr 2021 


\section{بررسى انطباق بيمار ستان امام خمينى تهران با استانداردهاى بيمار ستان دوستدار ايمنى بيمار در همهيرى كوويد- 19: يك مطالعه موردى}

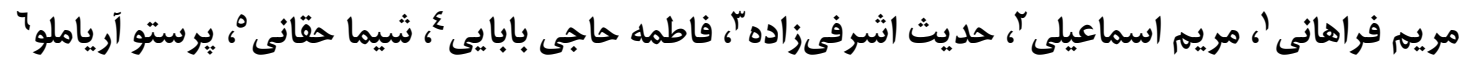

زمينه و هدف: انطباق صددرصدى با استانداردهاى الزامى بيمارستان دوستدار ايمنى بيمار مىبايست اولويت هر بيمارستان باشد. به دليل شيوع غير

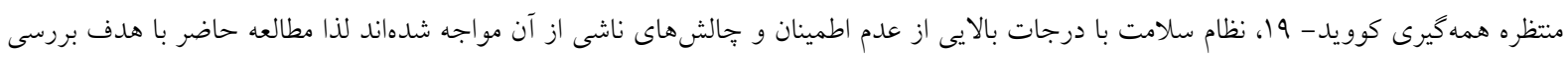

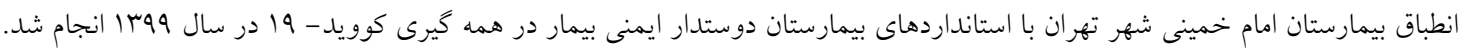

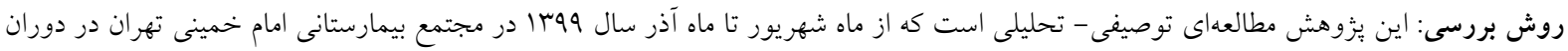

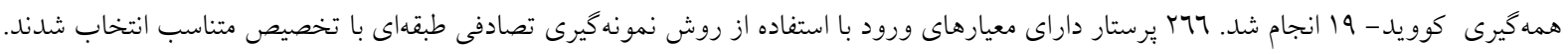

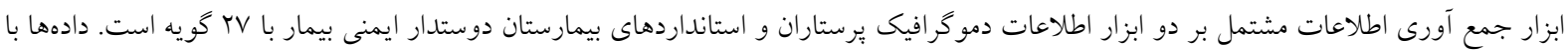

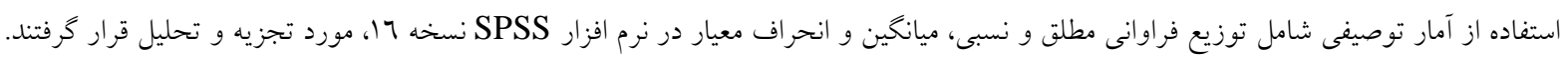

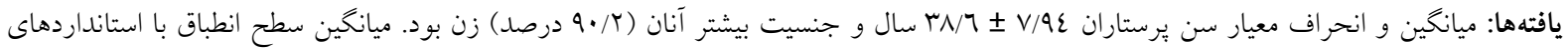

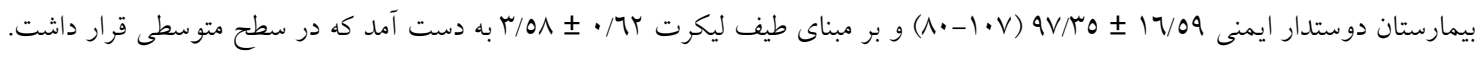
نتيجه گيرى كلى: به منظور بهبود وضعيت موجود مديريت هدفمند و مبتنى بر شواهد منابع سازمانى، توجه به موانع تحقق ابعاد ايمنى بيمار، نهادينه

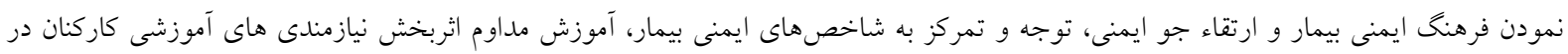

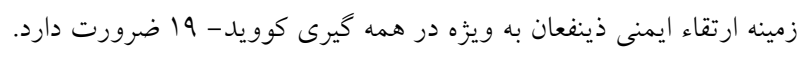

كليدوازهها: استاندارد، بيمارستان دوستدار ايمنى بيمار، برستار، ايمنى بيمار، كوويد 9 ا، همه گيرى.

$$
\text { تاريخ داريخ منافع: وجود ندارد. }
$$

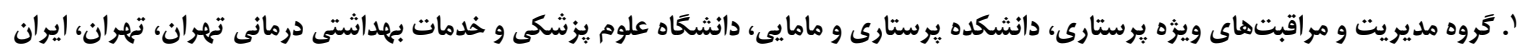

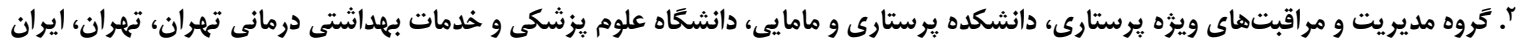

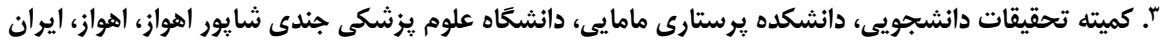

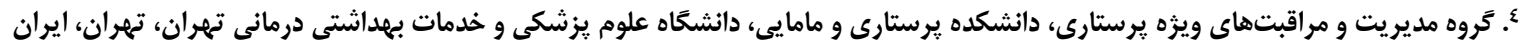

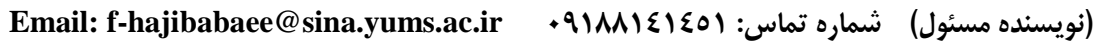

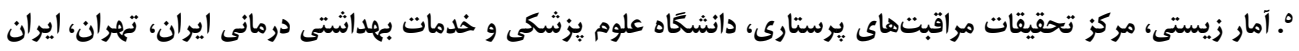

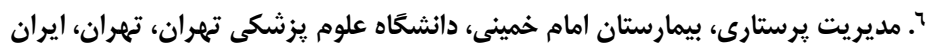


بنابراين در واكنش به دغدغههاى وضعيت موجود،، دفتر

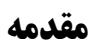

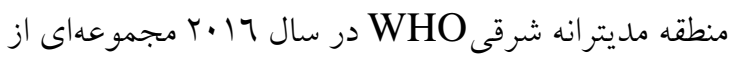

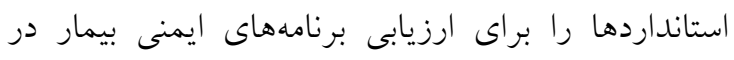

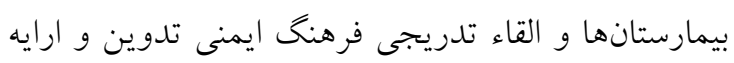

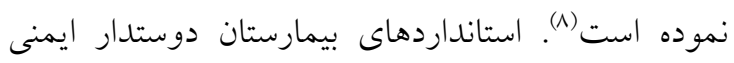

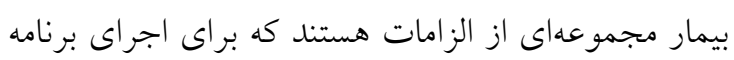
ايمنى بيمار در سطح بيمارستان حياتىاند. اين استانداردها

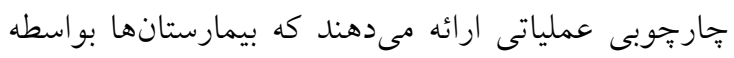
تحقق صددرصدى آنها با ابعاد ايمنى بيمار تطابق مى يابند

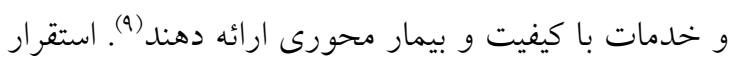

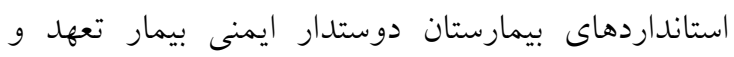
ياسخخكويى مسئولان را در زمينه ايمنى بيمار به جامعنه

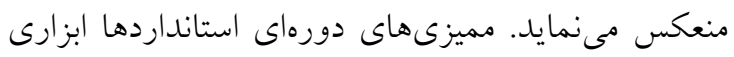
كليدى است كه نقاط ضعف را در زمينه ايمنى بيمار در سازمان ترسيم مىنمايدكه در نتيجه كاربرد مداخلات مؤثر

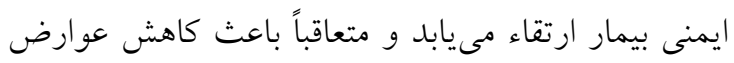

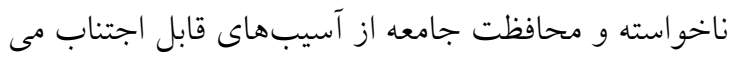
كردد نان (1). (1). همه كيرى كوويد- 19 از جمله بيمارىهاى عفونى نويديد مىباشد كه در طى ماههاى اخير، تمام دنيا دركير آن شده

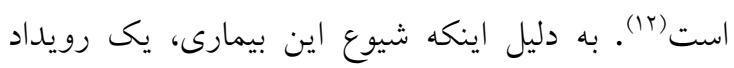

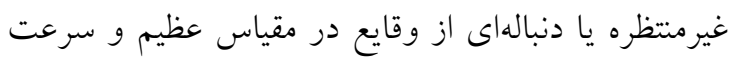

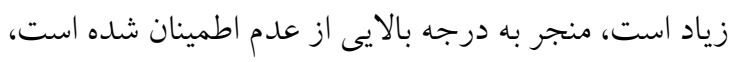

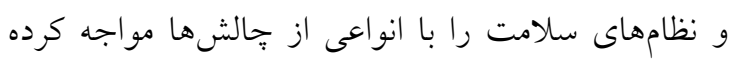

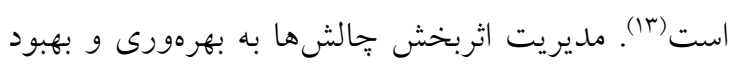

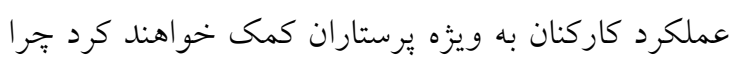
كه در شرايط فعلى در خط مقدم بيمارستانها به عنوان خط

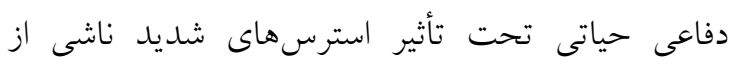

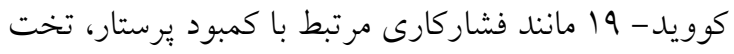

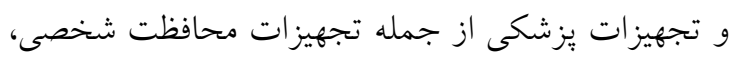

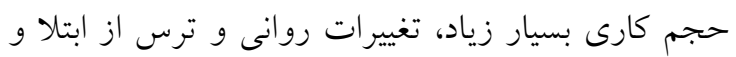

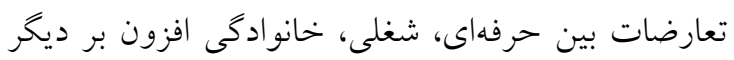
استرسهاى مربوط به شغل يرستارى از جمله نوبتهاى كارى در گردش و ساعتهاى كار طولانى و سختى كار امروزه بهبود كيفيت خدمات سلامت و عملكرد بهينه بيمارستانها يك موضوع جهانى و جزء اصلى ترين اهداف

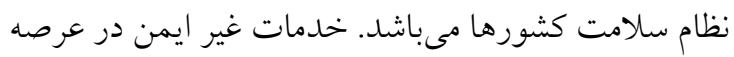
هاى سلامت معضلى كسترده و دغدغهاى جهانى است كه بـ بيماران را در تمامى عرصههاى خدمات سلامت در همه

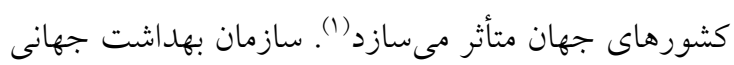

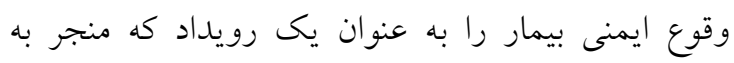

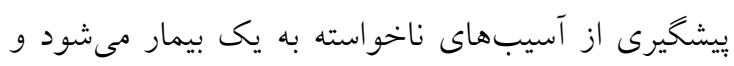
ناشى از اقدام عملكردى و سهوى است، تعريف مى كند (r).

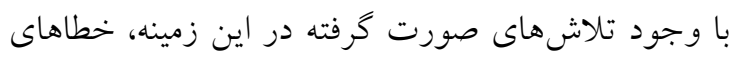

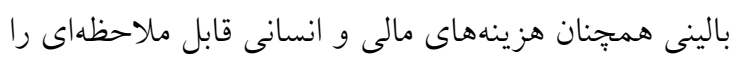

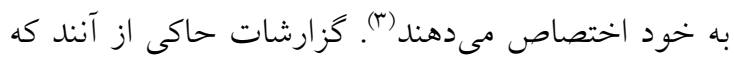

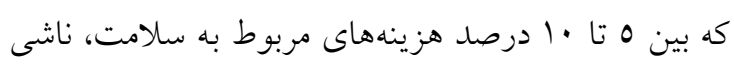

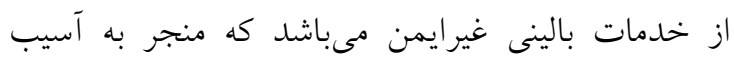

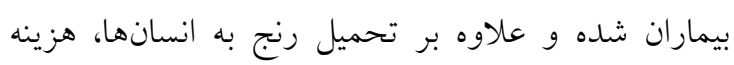

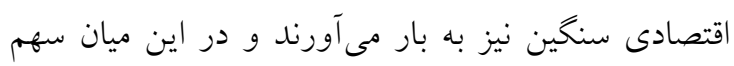

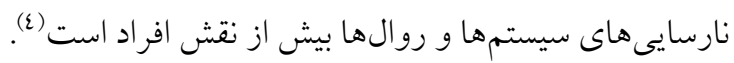

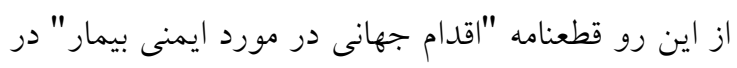

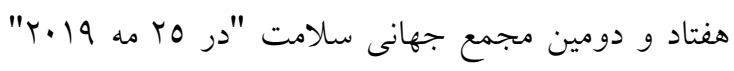
تصويب شد. اين قطعنامه، ايمنى بيمار را به عنوان يك دونى اولويت جهانى سلامت به رسميت شناخت و با تعيين روز

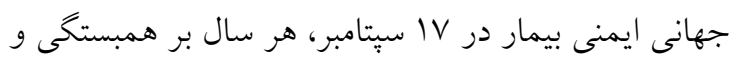
تعهل جهانى به منظور ايمن تر نمودن مراقبتهاى سلامت تأكيد نمود بيمارستان يكى از نهادهاى مهم ارايه خدمات بهداشتى ندانى

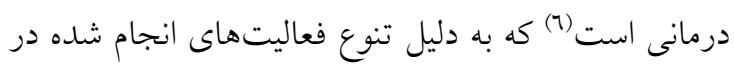

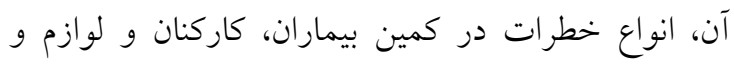

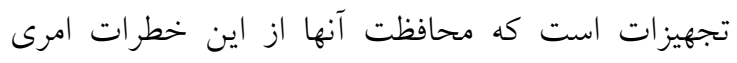

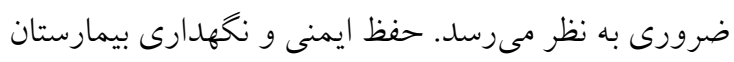
در شرايط ايمن، بايد جزو سياستهاى كلى بيمارستان

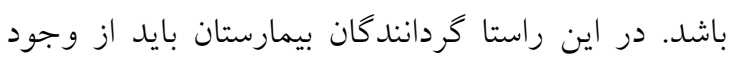

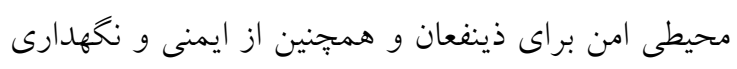
مناسب تجهيزات و تأسيسات اطمينان حاصل نمايند (v). 
آذر) در دوران همه كيرى كوويد- 19 انجام شد. مجتمع

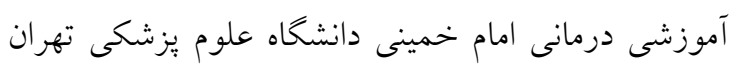
به عنوان محيط يزوهش انتخاب شد. جامعه آمارى، تمام

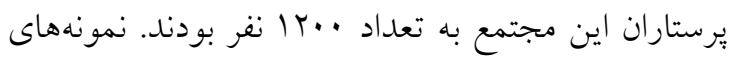

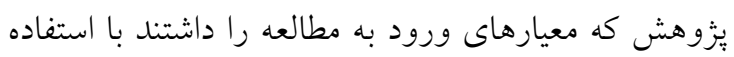
از نمونه كيرى به روش تصادفى طبقهاى با تخصيص

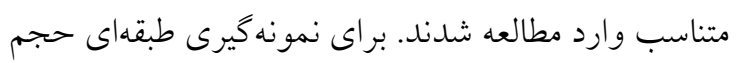

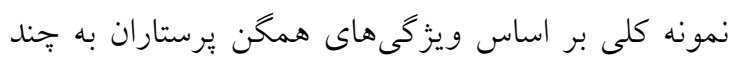

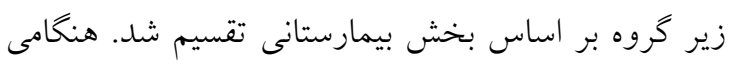

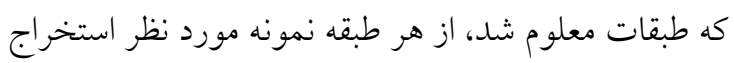
شد. استخر اج از طبقات به صورت مستقل انجام شده است.

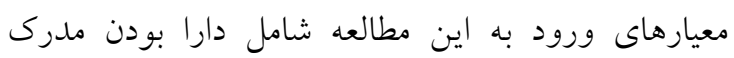
كارشناسى برستارى و بالاتر، سابقه كارى شش ماه به بالا

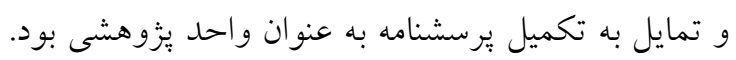

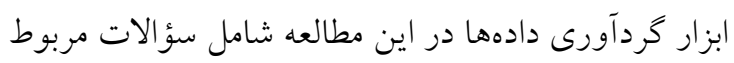

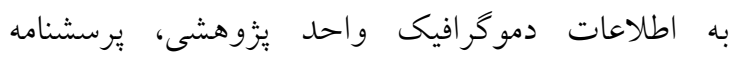

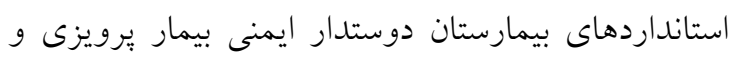

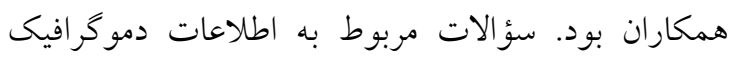

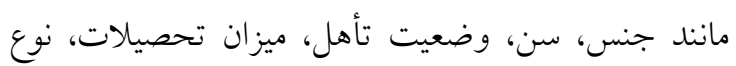

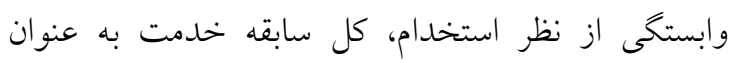

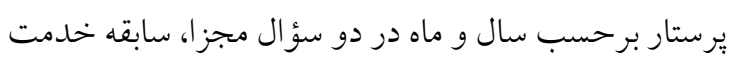

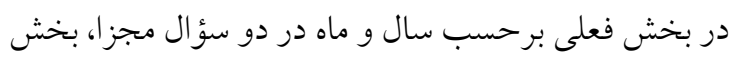

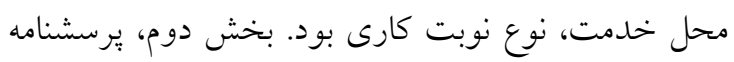

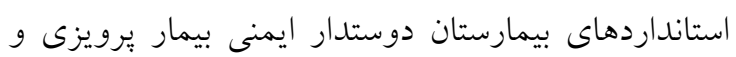

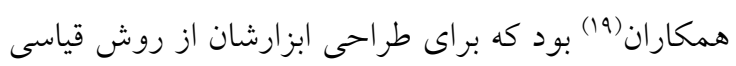

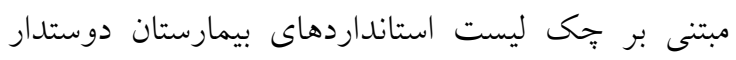

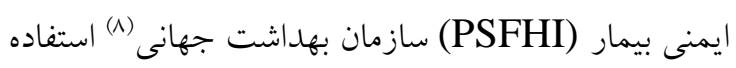

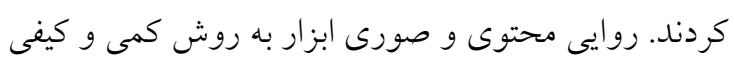

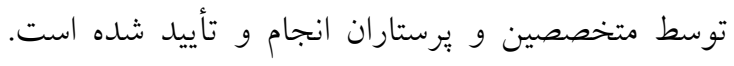

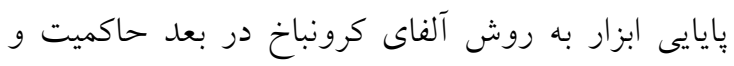

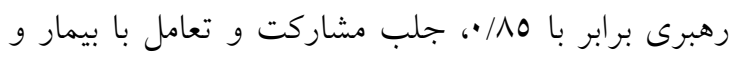

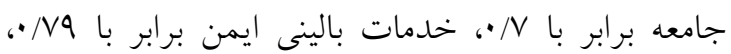

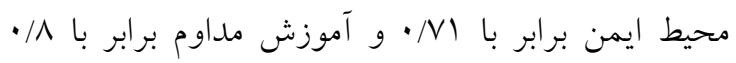

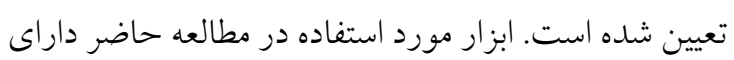

قرار دارند (17-1). فشار كارى و وظايف سنخين كادر درمان به ناميدى، استرس و از بين رفتن ارتباط با همكاران منجر

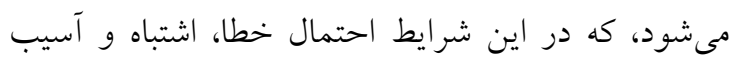
ديدن بيمار افزايش مى يابد (VV). در نتيجه ايمنى بيمار متأثر

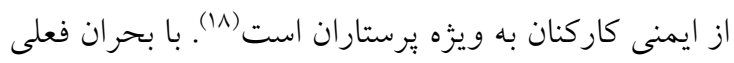

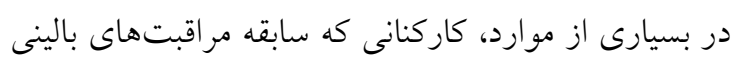

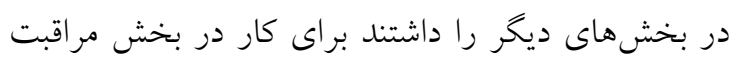

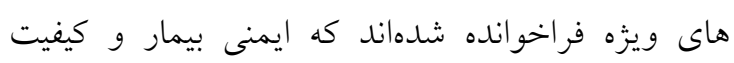
خدمات را تحت شعاع قرار داده است (1). از آنجايى كه تحقق صددرصدى استانداردهاى بيمارستان

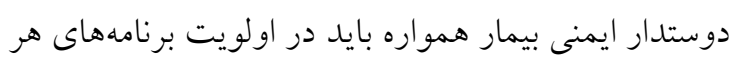

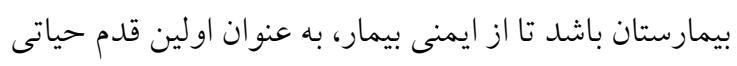

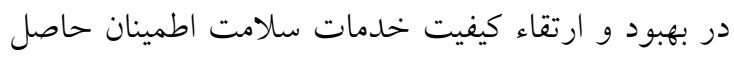

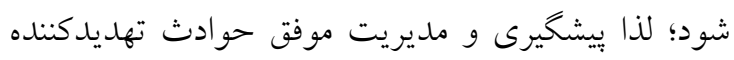
سلامت ذينفعان به منظور صيانت از سرمايه سلامتى و ارايه

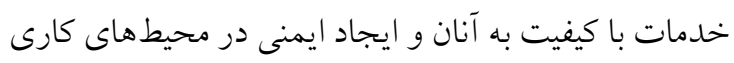
به ويزه حين بحرانها و إيدمىها در تمام سطوح نظام

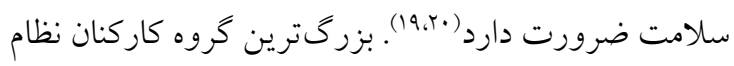
سلامت را يرستاران تشكيل مىدهند كه با بيشترين ميزان

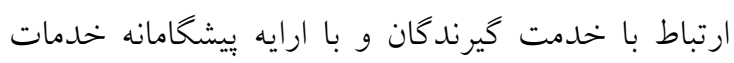
سلامت عليه انواع مشكلات سلامتى از حساسترين

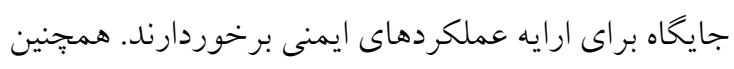

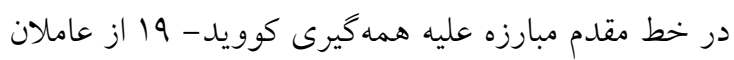
دفاعى حياتى محسوب مىشوند بنابر اين بررسى اين مقوله

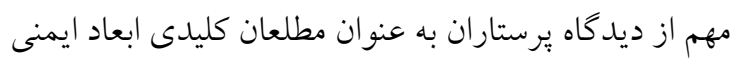

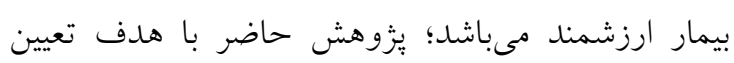

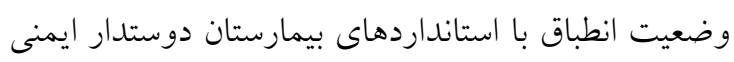

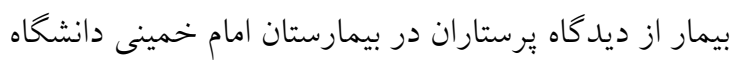

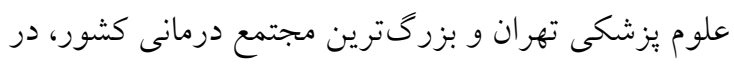

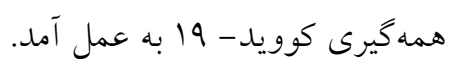

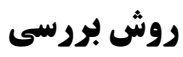

اين يزوهش مطالعهاى توصيفى - تحليلى از نوع مقطعى دورسى

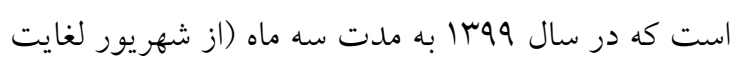


آنان ايجاد شد. سبس برستارانى كه در بخشهاى يكسان

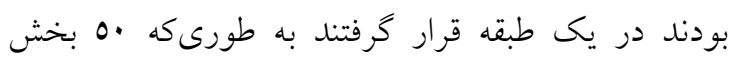

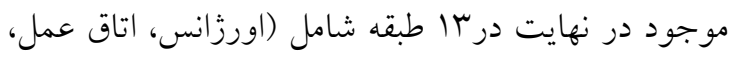
NICU ،CU ،ICU

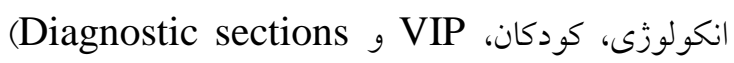
مديريت گرديدند. حجم نمونه مورد نياز با مقدار كذارى در

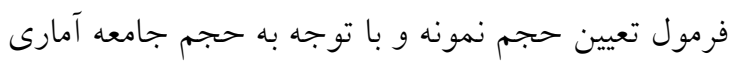

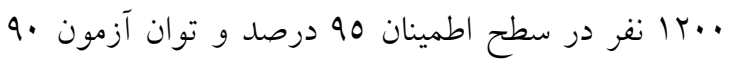
درصد به دست آمد. بنابر اين از ليست ملاكى مشتمل بر 177 يرستار و بر اساس سهميه يرستاران از سا طبقه موجود، به

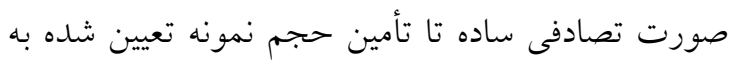
تعداد الج Y نفر با احتساب •ا درصد اضافه براى مديريت ريزش نمونها؛ كو نمونه انتخاب شدند. با توجه به همه

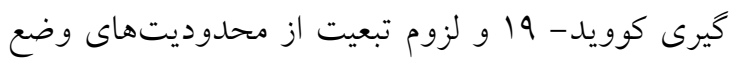
شده ناشى ار آن، جهت جمع آورى دادههاى مورد نياز

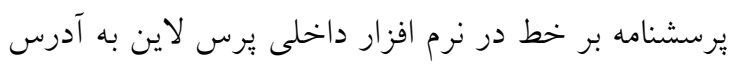
https://survey.porsline.ir/s/JctQYnD بخش مقدمه توجيهى، اطلاعات دموگر افيك يرستاران و

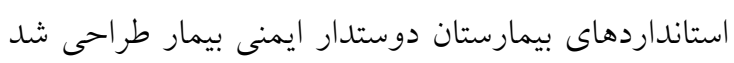

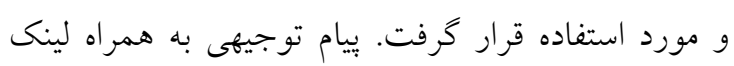

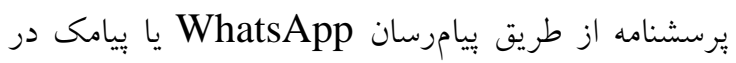

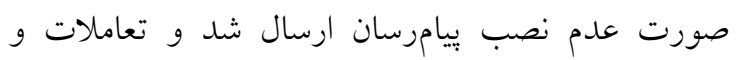

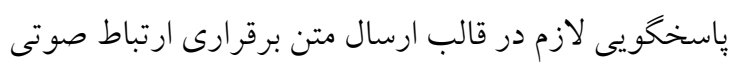

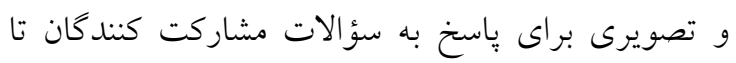

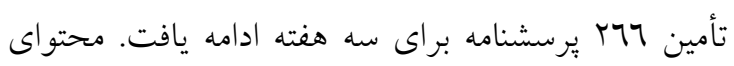

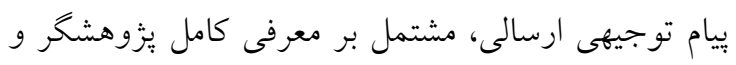

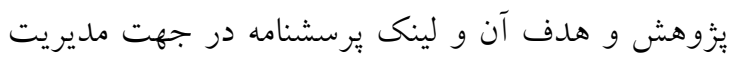
محدوديتهاى ناشى از نمونه كيرى برخط بود. در بيام

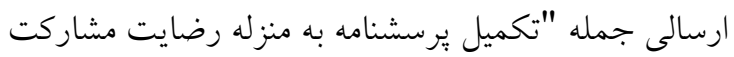
در مطالعه محسوب مى شود." درج شد و بنابر اين برستاران

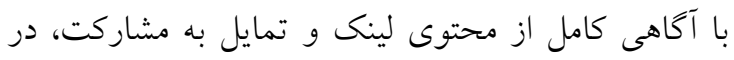

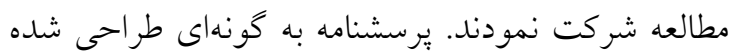

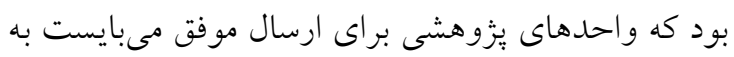

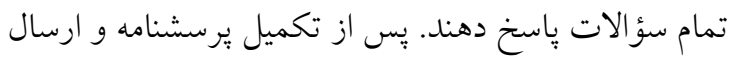

TV كويه و مشتمل بر ينج بعد حاكميت و رهبرى (شش

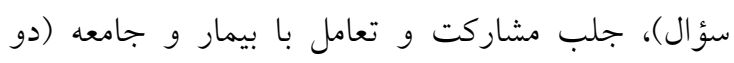
سؤال)، خدمات بالينى ايمن (هفت سؤال)، محيط ايمن

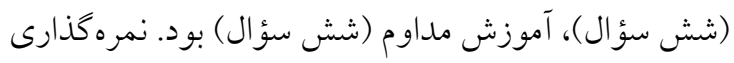

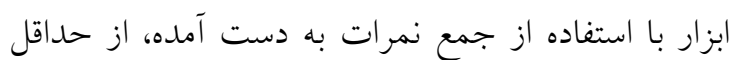

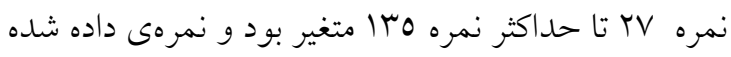
بالاتر از ديدكاه واحد يُزوهش به بماه معنى انطباق بيشتر

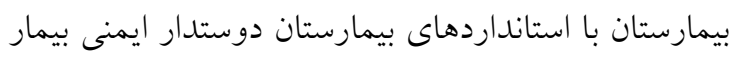

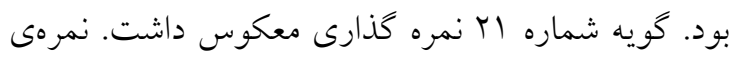

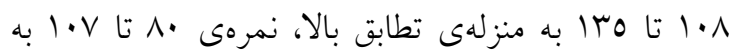

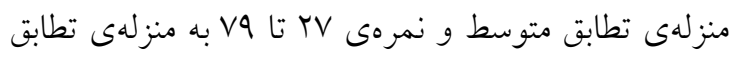
ضعيف بيمارستان با استانداردهاى بيمارستان دوستدار ايمنى بيمار در نظر كرفته شد (19).

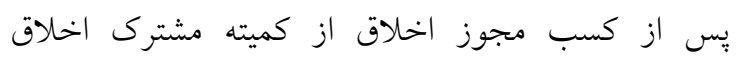

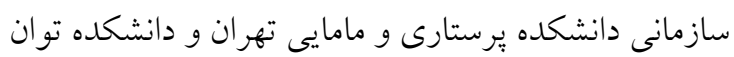
بخشى IR.TUMS.FNM.REC.1399.084 روايى صورى بخديخ

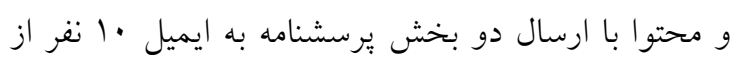
اعضاى هيئت علمى خبره در زمينه ايمنى بيمار دانشگاه

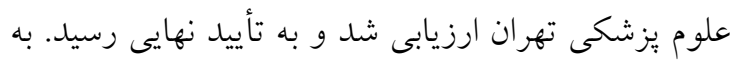

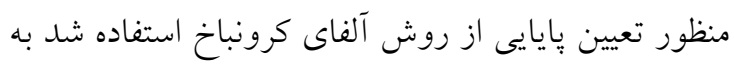

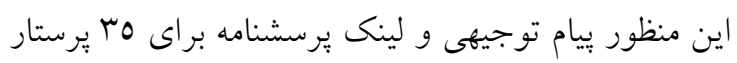

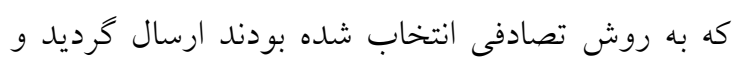

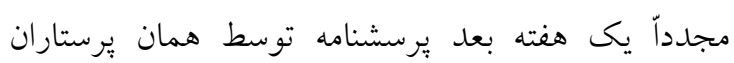

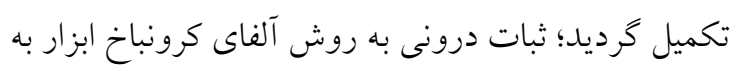

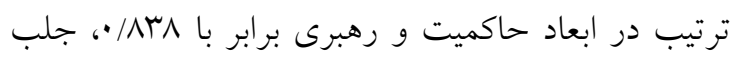

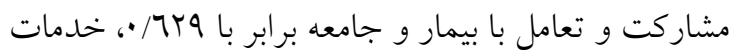

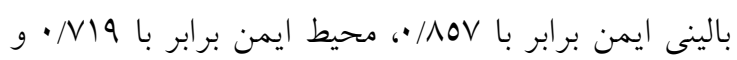

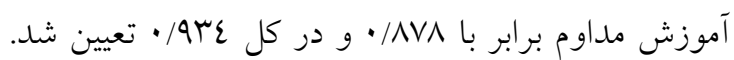

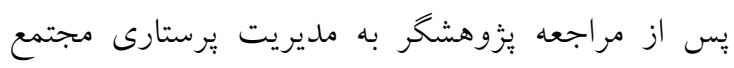

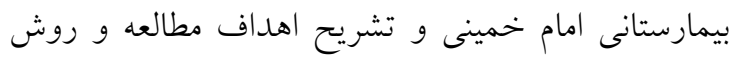
انجام كار؛ ليست مورد نياز از جامعه يُزوهشى به به تعداد بهاد IT...

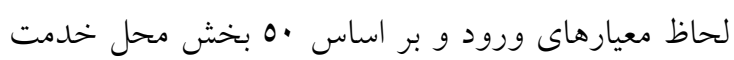


افراد متأهل با س/ه درصد داراى فراوانى بيشترى بودند. سطح تحصيلات / / אم درصد برستاران كارشناسى و نوع استخدام بيشتر آنها (TV/V) درصد) رسمى بود. ميانخين و انحراف معيار كل سابقه خدمت به عنوان برستار و سابقه

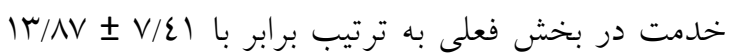

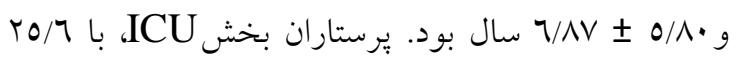
درصد نسبت به ساير بخشهاى بيمارستانى و همجٍنين نوبت كارى در گردش با ع/Yع درصد بيشترين فراوانى را داشتند (جدول شماره ()).
آن توسط هريك از واحدهاى يزّوهش، دادهها در ايميل يزؤهشخ ذخيره شدند. در نهايت اطلاعات ذخيره شده در ايميل يزوهش گر بازيابى شدند و دادهها با استفاده از آمار توصيفى شامل توزيع فراوانى مطلق و نسبى، ميانخين و انحراف معيار در نرم افزار SPSS نسخه 7 ا، مورد تحليل قرار كرفتند.

كافتهها نتايج نشان داد ميانخين و انحر اف معيار سن برستاران V/9ع

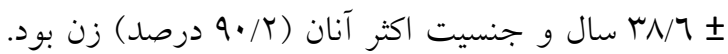

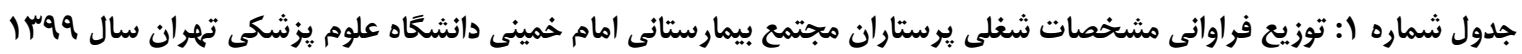

\begin{tabular}{|c|c|c|c|}
\hline درصد & فراوانى & & 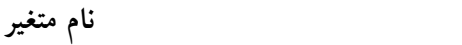 \\
\hline$T \cdot / V$ & 00 & • • بو كمتر & \\
\hline$\varepsilon \cdot / 0$ & $1 \cdot 1$ & $\mu_{1}-\varepsilon$. & \\
\hline$r / 0$ & 19 & $\sum 1-0$. & سن (سال) \\
\hline$O / r$ & $1 \varepsilon$ & بيشتر از -0 & \\
\hline $1 \ldots$ & rา7 & جمع كل & \\
\hline \multicolumn{2}{|c|}{$\Gamma_{N / \tau} \pm \pm V / Q \varepsilon$} & انحراف معيار 土 ميانك & \\
\hline \multicolumn{2}{|c|}{$r r-09$} & بيشينه - كمينه & \\
\hline$q \cdot / r$ & $r \varepsilon$. & زن - ت زن & \\
\hline $9 / 1$ & r & 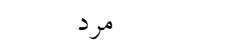 & جنس \\
\hline $1 \cdots$ & $r 77$ & جمع كل & \\
\hline$r q / 0$ & 1.0 & مجرد & \\
\hline $0 \Lambda / r$ & 100 & متأهل & وضعيت تأهل \\
\hline$T / T$ & 7 & ساير & \\
\hline $1 \cdots$ & rา7 & جمع كل & \\
\hline$\Lambda \mathcal{L} / \mathrm{r}$ & TYq & كارشناسى & \\
\hline $10 / 1$ & $\varepsilon r$ & كارشناسى ارشد & ميزان تحصيلات \\
\hline $1 \cdots$ & r77 & جمع كل & \\
\hline$T V / V$ & $1 \wedge$. & رسمى & \\
\hline $1 \% / 0$ & m & ييمانى & \\
\hline $0 / 7$ & 10 & طرحى & نوع استخدام \\
\hline$T \mu$ & 7 & قراردادى & \\
\hline $1 \cdot / 9$ & rq & شركتى & \\
\hline $1 \cdots$ & r77 & جمع كل & \\
\hline$r N / r$ & Vo & كمتر از •1 & كل سابقه خدمت به عنوان يرستار (سال) \\
\hline$\varepsilon V / V$ & ITV & $1 \cdot-19$ & \\
\hline$r \varepsilon / 1$ & $7 \varepsilon$ & 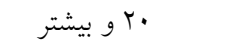 & \\
\hline
\end{tabular}




\begin{tabular}{|c|c|c|c|c|}
\hline $1 \cdots$ & & r77 & جمع كل & \multirow{11}{*}{ سابقه خدمت در بخش فعلى (سال) } \\
\hline & $|\Psi / \Lambda V \pm V / \varepsilon|$ & & انحراف معيار 土 ميانكين & \\
\hline & $1-r \cdot$ & & بيشينه- كمينه & \\
\hline$\varepsilon 7 / 7$ & & $T r \varepsilon$ & كمتر از & \\
\hline$r \varepsilon / \varepsilon$ & & 70 & $0-9$ & \\
\hline IV/V & & $\varepsilon V$ & $1 \cdot-1 \varepsilon$ & \\
\hline$\Lambda / 7$ & & rr & $10-19$ & \\
\hline$r / 7$ & & $\checkmark$ & ل الج و بيشتر & \\
\hline $1 \ldots$ & & r77 & جمع كل & \\
\hline \multicolumn{3}{|c|}{$V / \wedge V \pm 0 / \wedge$} & انحراف معيار 土 ميانكين & \\
\hline & $1-T V$ & & بيشينه- كمينه & \\
\hline$\Lambda \mu$ & & rr & 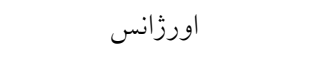 & \\
\hline $1 / 9$ & & 0 & اتاق عمل & \\
\hline ro/7 & & $u$ & $\mathrm{ICU}$ & \\
\hline$r / \Lambda$ & & 1. & $\mathrm{CCU}$ & بخش بيمارستان \\
\hline r & & $\wedge$ & $\mathrm{NICU}$ & \\
\hline $1 / 0$ & & $\varepsilon$ & بخش دياليز & \\
\hline $10 / 1$ & & $\varepsilon r$ & بخش جراحى & \\
\hline $10 / 2$ & & $\varepsilon$ & بخش داخلى & \\
\hline $11 / \mathrm{V}$ & & r & هماتولوزى، خون و سرطان & \\
\hline$r / \varepsilon$ & & 9 & بخش عفونى & \\
\hline$r / \Lambda$ & & $1 \cdot$ & بخش هاى تشخيصى & \\
\hline$\varepsilon / r$ & & 11 & VIP & \\
\hline $1 / 9$ & & 。 & بخش اطفال & \\
\hline $1 \cdots$ & & 177 & جمع كل & \\
\hline$r \varepsilon / \Lambda$ & & 77 & صبح & \\
\hline$\cdot / \wedge$ & & r & عصر & \\
\hline 7 & & 17 & شب & نوع نوبت كارى \\
\hline $1 \cdot / r$ & & TV & عصر و شب & \\
\hline $10 / 1$ & & $\varepsilon r$ & صبح و عصر & \\
\hline$\varepsilon T / \varepsilon$ & & 114 & مركردش & \\
\hline $1 \cdot$. & & r77 & جمع كل & \\
\hline
\end{tabular}

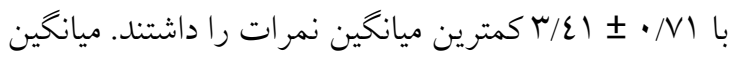
نمرات ابعاد محيط ايمن، جلب مشاركت و تعامل با بيمار

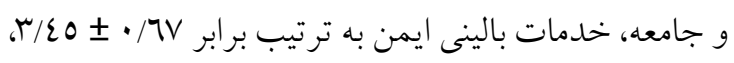

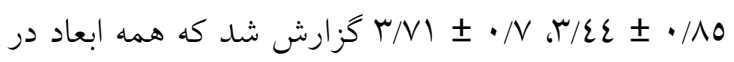
سطح متوسطى قرار داشت. (جدول شماره Y).
ميانخين نمره انطباق با استانداردهاى بيمارستان دوستدار

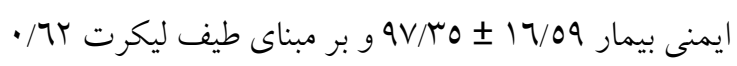
r/ON \pm

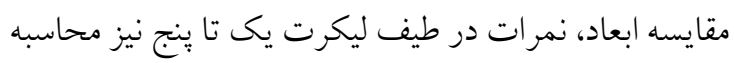

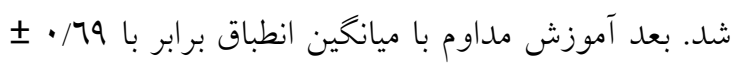

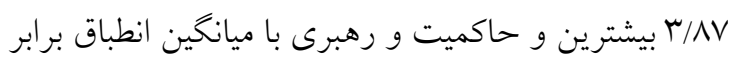




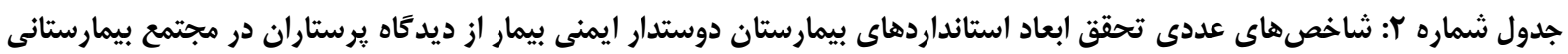

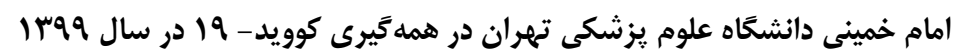

\begin{tabular}{|c|c|c|c|c|c|c|}
\hline \multicolumn{3}{|c|}{ بر مبناى ليكرت ا تاه } & \multirow[t]{2}{*}{ بيشينه } & \multirow[t]{2}{*}{ كمينه } & \multirow{2}{*}{ انحر اف معيار } & \multirow{2}{*}{ استانداردهاى بيمارستان دوستدار ايمنى بيمار و } \\
\hline بيشينه & كمينه & انحر اف معيار \ ميانگين & & & & \\
\hline 0 & 1 & $r / \varepsilon 1 \pm \cdot / N 1$ & r. & 7 & $r \cdot / 01 \pm \varepsilon / r q$ & حاكميت و رهبرى (·r-7) \\
\hline$\circ$ & 1 & $r / \varepsilon \varepsilon \pm \cdot / \wedge 0$ & 1. & r & $7 / 19 \pm 1 / 21$ & جلب مشاركت و تعامل با بيمار و جامعه (•l-Y) \\
\hline$\circ$ & 1 & $r / v I \pm \cdot / v$ & ro & $v$ & $r 0 / 97 \pm \varepsilon / 9 r$ & خدمات بالينى ايمن (V-ro) \\
\hline$\circ$ & $1 / 7 \vee$ & $r / 20 \pm \cdot / 7 V$ & $r$. & $1 \cdot$ & $r \cdot / V Y \pm \varepsilon / \cdot \varepsilon$ & محيط ايمن (·r-7) \\
\hline ० & 1 & $r / \Lambda V \pm \cdot / 79$ & $r \cdot$ & 1 & $r r / r o \pm \varepsilon / 19$ & آموزش مداوم (·r-7) \\
\hline 0 & $1 / 1 \pi$ & $r / 0 \Lambda \pm \cdot / T r$ & 1ro & $\mu$ & $9 / \pi 0 \pm 17 / 09$ & 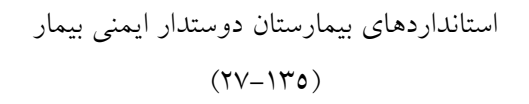 \\
\hline
\end{tabular}

در بعد حاكميت و رهبرى بيشترين و كمترين ميانخين به

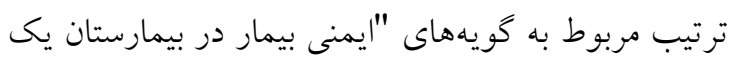
اولويت استراتزيك مىباشد و در قالب برنامه عملياتى مرئي

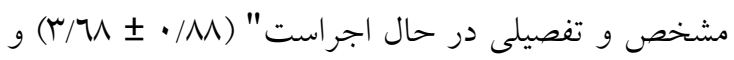

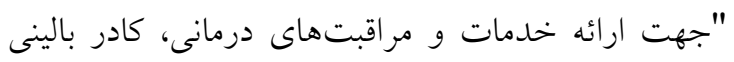
حائز شر ايط توسط كميته ذيصلاح به صورت ثابت و موقت دون

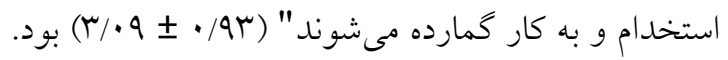
در بعد جلب مشاركت و تعامل با بيمار و جامعه بيشترين

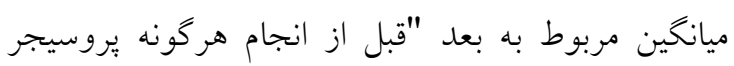

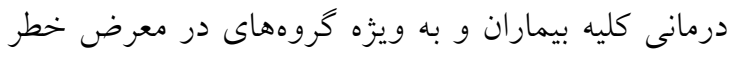

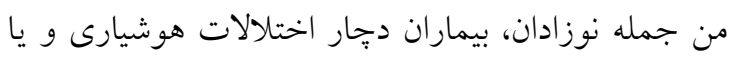
سالمندان حداقل با دو شناسه شامل نام و نام خانوادكى توزي مددجو و تاريخ تولد شناسايى و احراز هويت مى گردند. (هيج كاه شماره اتاق و تخت بيمار يكى از اين شناسهها

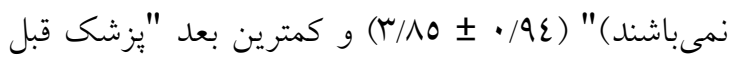
از انجام هركونه اقدام درمانى و تشخيصى تهاجمى، كليه

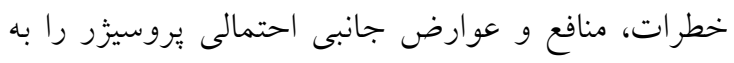

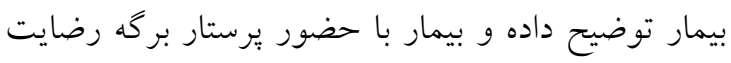

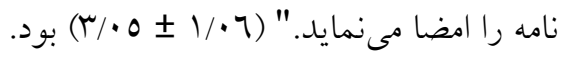

همانطور كه در جدول شماره r مشاهده مىشود ديدكاه

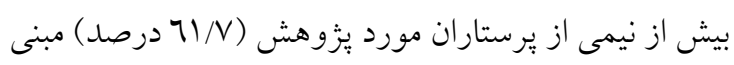

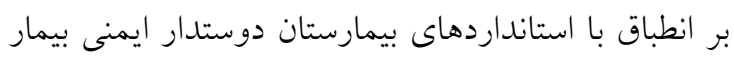

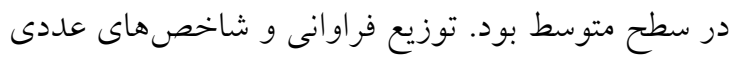
ابعاد استانداردهاى بيمارستان دوستدار ايمنى بيمار از بردئ

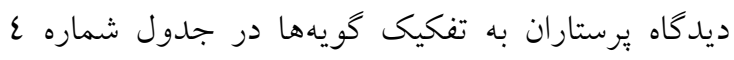
آورده شده است.

جدول شماره rا: توزيع فراوانى انطباق بيمارستان با ديا

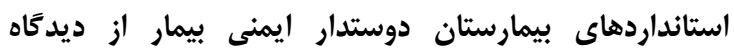

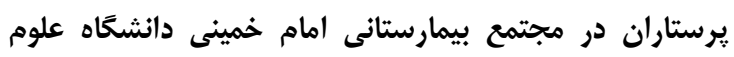

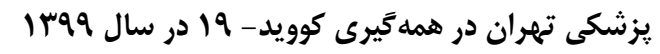

\begin{tabular}{|c|c|}
\hline (درصد) فراوانى & 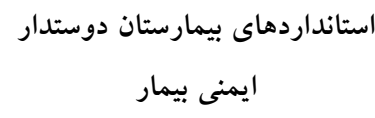 \\
\hline$\mu_{\varepsilon}(1 \% / \Lambda)$ & ضعيف (TV-V9) \\
\hline $17 \varepsilon(71 / V)$ & متوسط (v• • • (^) \\
\hline$\eta(T 0 / 7)$ & بالا (r.1- 1.1) \\
\hline rา7 (1..) & جمع كل \\
\hline
\end{tabular}





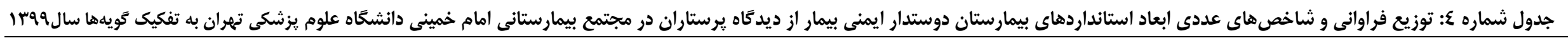

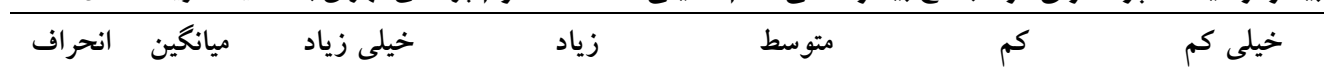

\begin{tabular}{|c|c|c|c|c|c|c|c|c|c|c|c|c|c|}
\hline 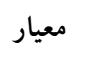 & & ل مرصد & 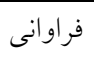 & ل مرصد & 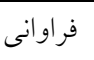 & ل مرصد & 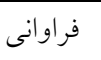 & مرصد & 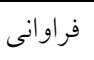 & ل مرصد & فر او انى ل & 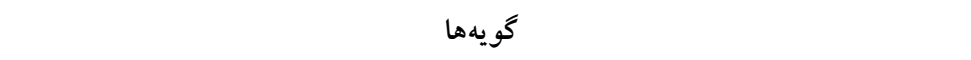 & ابعاد اد \\
\hline$\cdot / \mathrm{M}$ & $r / \neg \Lambda$ & $I V / N$ & $\varepsilon V$ & $\sum 1$ & 1.9 & ro/v & 90 & $r / \varepsilon$ & 9 & $r \mu$ & 7 & ايمنى بيمار در بيمارستان يك اولويت استراتزيك مىباشد و در قالب برنامه عملياتى مشخص & \\
\hline & & & & & & & & & & & & و تفصيلى در حال اجراست. & \\
\hline $1 / \cdot r$ & $r / r q$ & ir & re & $r q / r$ & vı & $\varepsilon \cdot / 7$ & $1 \cdot 1$ & $11 / \pi$ & r. & $7 / 1$ & 11 & 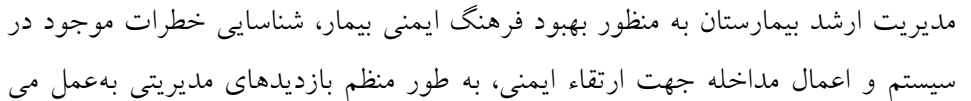 & \\
\hline
\end{tabular}

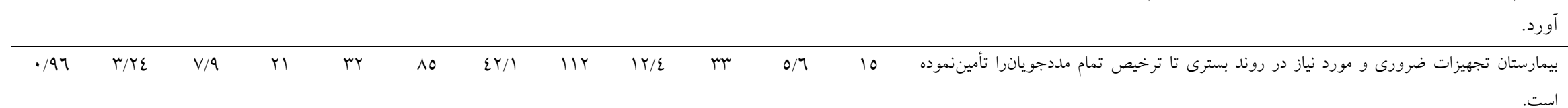

\begin{tabular}{|c|c|c|c|c|c|c|c|c|c|c|c|c|}
\hline.$/ 90$ & $r / 09$ & $17 / 9$ & ¿o & $\mu_{\Lambda}$ & 1.1 & $r \mathrm{r} / \mathrm{l}$ & 97 & $0 / \Gamma$ & $1 \varepsilon$ & $r / \Lambda$ & 1. & مطلوب را به عمل مى آورد. \\
\hline$\cdot / 9 \varepsilon$ & $r / \neg r$ & $1 N / 2$ & $\varepsilon q$ & $r V / r$ & 99 & ro/v & 90 & $0 / 7$ & 10 & $r$ & $\wedge$ & بيمارستان به منظور تضمين ضدعفونى و استريليزاسيون،داراىوسايلوتجهيزات كافىمىباشد. \\
\hline . $/ 94$ & $r / \cdot q$ & $0, \varepsilon$ & IT & $r q / r$ & V^ & $\sum 1 / V$ & 111 & $19 / 4$ & 01 & $0 / r$ & $1 \varepsilon$ & 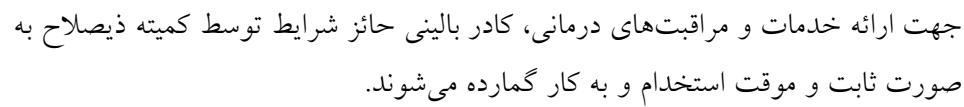 \\
\hline
\end{tabular}

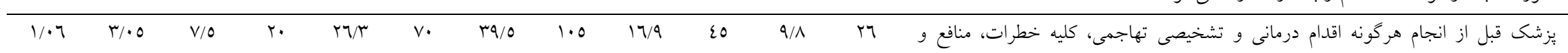

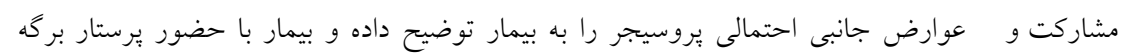
تعامل با بوضايت نامه را امضا مئمايد.

\begin{tabular}{|c|c|c|c|c|c|c|c|c|c|c|c|c|c|}
\hline$\cdot / 9 \varepsilon$ & r/^o & $r \varepsilon / \varepsilon$ & 70 & $\varepsilon V / \varepsilon$ & $1 Y 7$ & 11 & $\varepsilon \wedge$ & $\Lambda / 7$ & rr & $1 / 0$ & $\varepsilon$ & 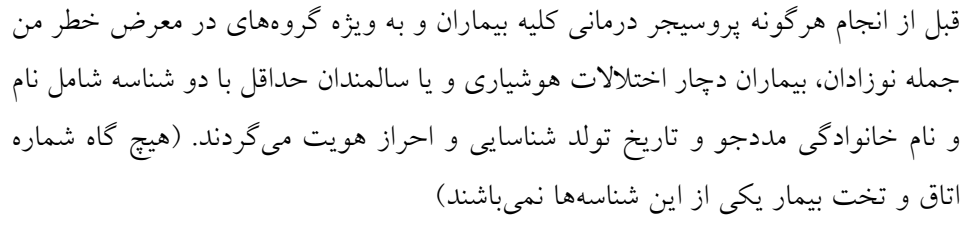 & 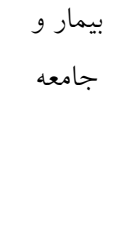 \\
\hline $1 / \cdot 1$ & $\varepsilon / \cdot 1$ & $\mu$ & 1.1 & $\mathrm{ra} / \mathrm{\Lambda}$ & 91 & $17 / r$ & $\varepsilon r$ & $7 / \varepsilon$ & IV & $r / 7$ & $v$ & بينى كرده است. بيمارستان به منظور اعلام اضطرارى نتايج حياتى آزمايشها، خطوط تلفن همواره آزاد بِيش & خدمات \\
\hline$\cdot / \cdot V$ & $\Gamma / \Lambda$ & $11 / \mu$ & $r$. & $r \tau / r$ & $v$. & $\mathrm{rq} / \mathrm{o}$ & 1.0 & $\mid \varepsilon / V$ & $r q$ & $\Lambda \mu$ & Tr & بعبد از ترخيص متان داراى روالهاى مطمئن، براى اعلام نتايج معوقه تستهاى بار اكلينيكى به بيماران & بالينى ايمن \\
\hline
\end{tabular}




\begin{tabular}{|c|c|c|c|c|c|c|c|c|c|c|c|c|c|}
\hline.$/ 91$ & $r / \neg \varepsilon$ & $17 / 0$ & $\varepsilon \varepsilon$ & $\sum Y / 0$ & $11 \pi$ & $r \cdot / \Lambda$ & $\Delta r$ & $1 / 7$ & $\mu^{\mu}$ & $1 / 0$ & $\varepsilon$ & ربيمارستان داراى برنامه يِشخيرى و كنترل عفونت مشتمل بر جارت سازمانى، برنامه عملياتى، & \\
\hline $1 / .7$ & $r / \varepsilon r$ & $1 \varepsilon / \mu$ & $\mu_{\Lambda}$ & $\mathrm{ru} / \mathrm{o}$ & $9 V$ & $\mu / 0$ & 19 & $\Lambda / 7$ & $\mu^{\mu}$ & $V / 1$ & 19 & 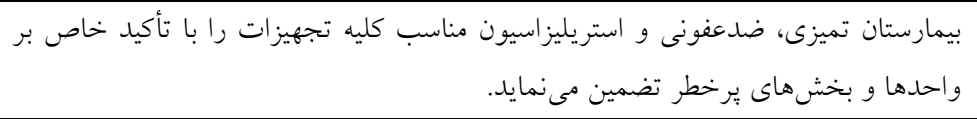 & \\
\hline . Ar & $r / 99$ & $r V / \Lambda$ & $V \varepsilon$ & $\varepsilon V / V$ & ITV & $r \cdot / V$ & 00 & $r$ & $\wedge$ & $\cdot / \Lambda$ & $r$ & فيمآوردهارستان راهنماهاى معتبر از جمله راهنى ايمن اجراهاى سازمان انمايد. جهانى بهداشت را در زمينه خون و & \\
\hline.$/ 90$ & $r / \Lambda$. & $r r / V$ & Tr & $\sum r / q$ & $11 \varepsilon$ & ro/7 & $u$ & $O / r$ & $1 \varepsilon$ & $r / 7$ & V & و غيمارستان داراى روش هاى اجرى خون در مواردى مانيى ايمن قبل از انتقال خون مانند ثبت نام، ردو و قبول داوطلبين & \\
\hline$\cdot / 10$ & $r / 9 \varepsilon$ & $r O / 9$ & 79 & $\varepsilon V$ & Iro & $r M / 1$ & 07 & $r$ & $\wedge$ & $1 / 0$ & $\varepsilon$ & بيمارستان دسترسى به داروهاى حياتىر ادرتمامى ساعاتشبانهروز (ع باعته) تضمين مىنمايد. & \\
\hline . /AT & $\varepsilon / \cdot \varepsilon$ & $r \cdot / 1$ & $\wedge$. & $\varepsilon \wedge / 0$ & 119 & $I V / V$ & $\varepsilon V$ & $r / 7$ & V & $1 / 1$ & $r$ & بيمارستان يُماندها را بر اساس ميزانخطر،ازمبدادركيسهاىرنخى تفكيكو كدبندىمىنمايد. & \multirow{6}{*}{ محيط } \\
\hline$\cdot / V q$ & $\varepsilon / . q$ & $r T / N$ & $\Lambda V$ & $\varepsilon V / V$ & ITV & $17 / r$ & \{\rceil & $r$ & $\wedge$ & $\cdot / \varepsilon$ & 1 & 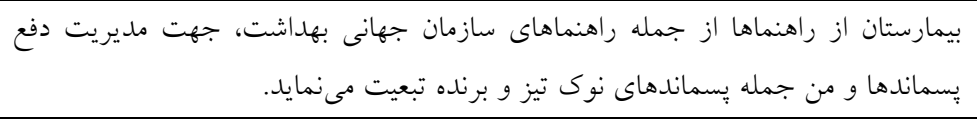 & \\
\hline $1 / \pi$ & r/o. & $0 / 7$ & 10 & $1 \varepsilon / \mu$ & rی & 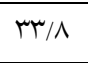 & 9. & IV/r & $\varepsilon 7$ & $r \wedge / 9$ & VV & من احساسمى كنم مدير يت بيمارستاننخر انوضعيتسلامتروحىوجسمى كار كنان اينبيمارستان است. & \\
\hline$\cdot / 19$ & $r / r \Lambda$ & $1 \% / 0$ & ry & TM/T & Vo & rN/V & $1 . r$ & IT & m & $\mathrm{V} / 0$ & r. & مديريت بيمارستان هنگام بروز يكى مسأله ايمنى به صورت قاطع برخورد مى كند. & \\
\hline$\cdot / 19$ & $r / r r$ & $\Lambda / r$ & rr & $r \varepsilon / r$ & 91 & $\sum 1 / N$ & 111 & $1 \pi / T$ & ro & $r / 7$ & V & تا ترخيص ماملان انجام فرآيندهاى تعريف شده، قوانين ايمنى مربوط به هر فرآيند رادر روند بسترى & \\
\hline $1 / \cdot 1$ & $r / \varepsilon \wedge$ & $r / \varepsilon$ & 9 & 1.10 & rA & $\Gamma_{\Lambda / r}$ & $1 . r$ & $r 9 / V$ & $\mathrm{Vq}$ & 11 & $\varepsilon \wedge$ & *مديريتبيمارستانمعمولاًرويهها، دستور العمل هاوقوانين ايمنى نقض شده، را ناديده مى گيرد. & \\
\hline $1 / \cdots 1$ & $r / \neg r$ & $19 / 0$ & or & $\mu_{\Lambda}$ & 1.1 & $\mu r / \mu$ & 17 & $0 / 7$ & 10 & $\varepsilon / 0$ & Ir & در محيط كار خود مىتوانم آنجه را كه آموختهام؛ به كار بخيرم. & \multirow{6}{*}{ مداوم - مآموش } \\
\hline.$/ 91$ & $r / \varepsilon \wedge$ & $1 \varepsilon / \Lambda$ & $\varepsilon r$ & 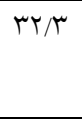 & 17 & $r q / 1$ & $1 \cdot \varepsilon$ & $9 / \varepsilon$ & ro & $\Gamma / \varepsilon$ & 9 & دانش جدينان دارم كه مى توانم بر موانع شغلى كه باعث به تعويق افتادن به كارگيرى مهارتها يا & \\
\hline$\cdot / 10$ & $r / q r$ & $r V / \Lambda$ & $V \varepsilon$ & $\varepsilon Y / l$ & 111 & $r 】 / V$ & VI & $r / r$ & 7 & $1 / 1$ & $r$ & غر اين بيمارستان در جهت توانمندسازى شغلى يرستاران كلاس هاى آموزشى حضورى يا & \\
\hline$\cdot / V q$ & $\varepsilon / \cdot r$ & $r N / r$ & vo & $0 . / 1$ & 1ro & $1 N / \Lambda$ & 0. & $\cdot / \Lambda$ & r & $1 / 0$ & $\varepsilon$ & هر جها آمو ز هاى علمى بيشترى درحيطهشغلى خو ددريافتمىنمايم،كارخودر ابهتر انجاممىدهم. & \\
\hline$\cdot / \mathrm{VI}$ & $\varepsilon / 1 \mathrm{r}$ & $r \cdot / \Lambda$ & Nr & or/A & $1 \varepsilon r$ & $1 \% / 0$ & ru & $\cdot / 2$ & 1 & $1 / 0$ & $\varepsilon$ & بكار گيرى آموخته هاى جديد سبب مى شود در انجام وظايف خود تسلط بيشترى داشته باشم. & \\
\hline$\cdot|\wedge|$ & $\varepsilon / \cdot\urcorner$ & $r \cdot / 1$ & $\wedge$. & $0 . / 1$ & 1ro & $17 / 0$ & $\varepsilon \varepsilon$ & $\cdot / 1$ & $r$ & $1 / 9$ & 0 & كاربر ددانش،نخرشومهارت هاى كسبشدهدرمحيط كارى من،باعث بهبو دنتايجسازمانى مى گردد. & \\
\hline
\end{tabular}


آنها بود، انجام شده است ايمنى بيماران را از ديدكاه بيش

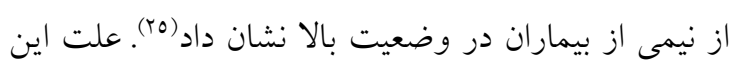

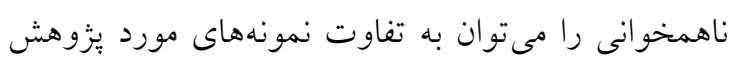
در دو مطالعه نسبت داد. زيرا در مطالعه ياد شده مددجويان

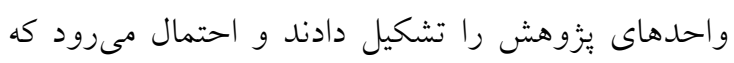

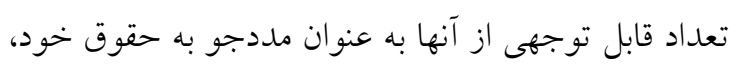

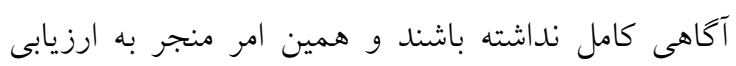
بالاتر وضعيت ايمنى بيمار شده باشد. شهيرى و همكاران

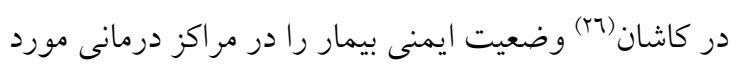
مطالعه در سطح ضعيف گزارش نمودند.

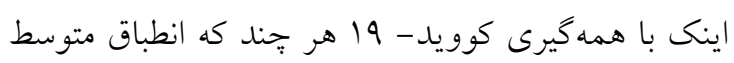
با استانداردهاى مورد نظر در اين مجتمع قابل توجه مي هي هئ

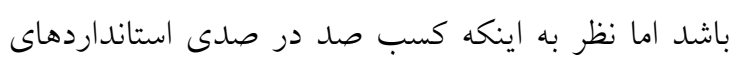
الزامى در تمامى ابعاد استانداردهاى بيمارستان دوستدار ايمنى بيمار براى دستيابى به حداقل سلى سطح بيمارستان

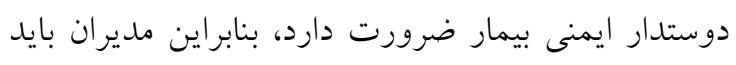

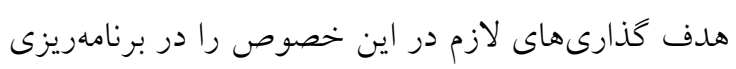

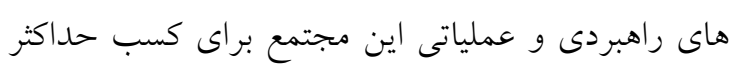

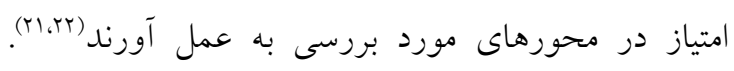

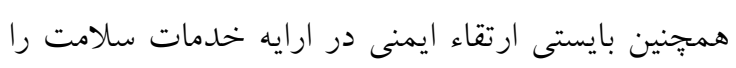

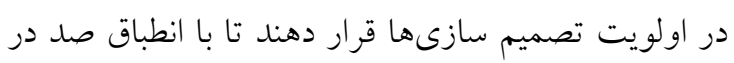

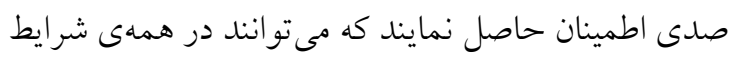

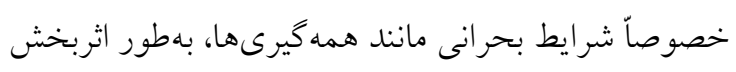

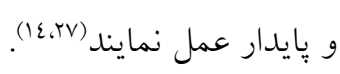
بيشترين سطح انطباق مربوط به بعد آموزش مداوم بود.

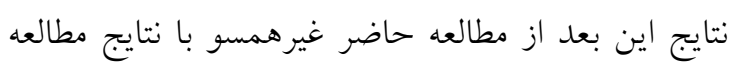
نجف يور و همكاران است كه وضعيت آموزش در زمينه

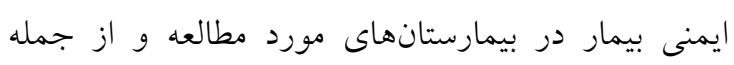

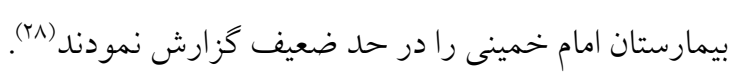
در كزارش كميته وزارتخانه متعلق به انجمن ارويا با عنوان

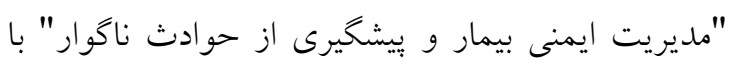

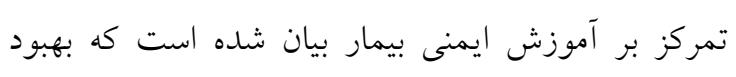

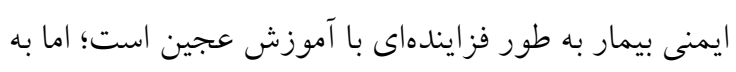

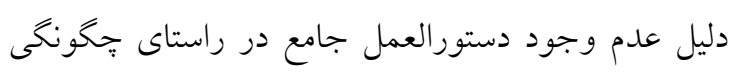

در بعد خدمات بالينى ايمن بيشترين و كمترين ميانخين به ترتيب مربوط به خويههاى "بيمارستان به منظور اعلام

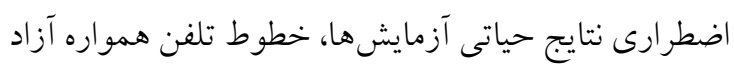

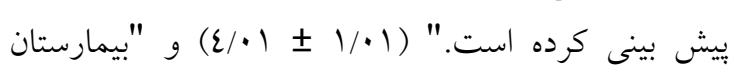

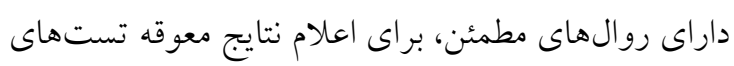

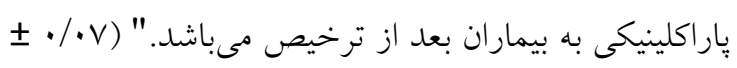

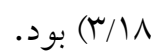

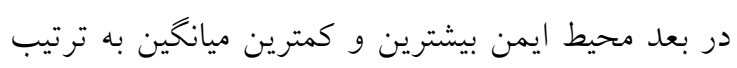

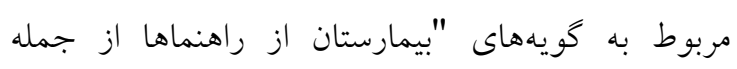

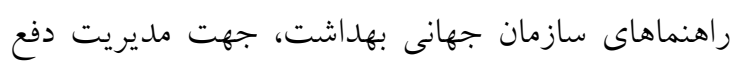
״سماندها و من جمله پِماندهاى نوى تيز و برنده تبعيت

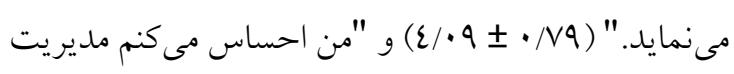
بيمارستان نخر ان وضعيت سلامت روحى و جسمى كار كنان

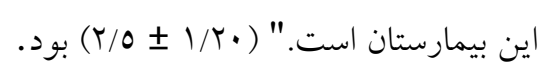
در بعد آموزش مداوم بيشترين و كمترين ميانخين به ترتيب

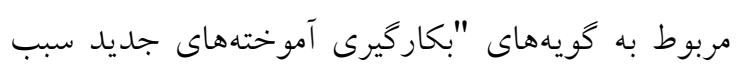
مىشود در انجام وظايف خود تسلط بيشترى داشته باشم."

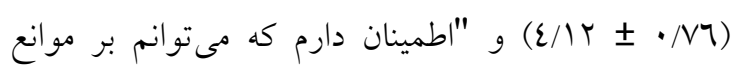

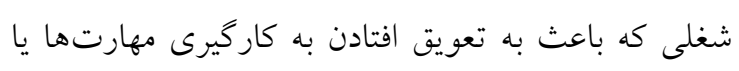

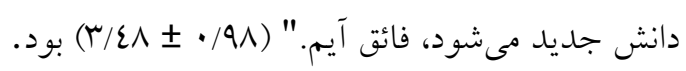

\section{بحث و نتيجه كيرى}

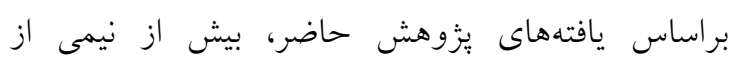

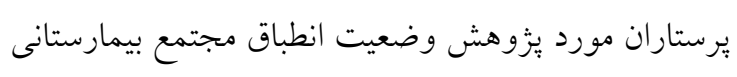

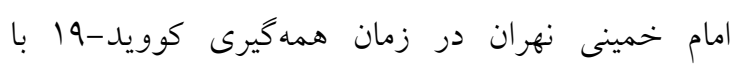

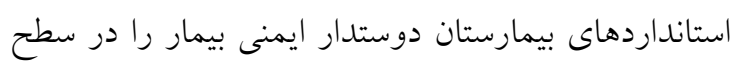

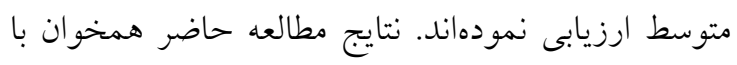

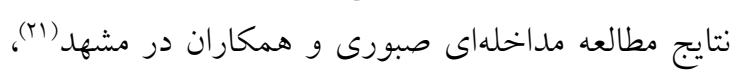
مطالعه اكبرى و همكاران در اروميه (rr)، جبارى و همكار همان

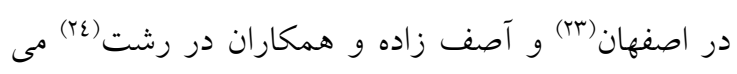
باشد. علت همسويى اين مطالعات را مىتوان به تشابه

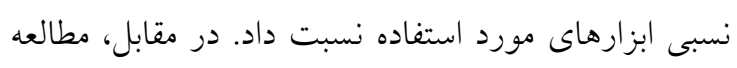
سارى و همكاران كه در شش بيمارستان وابسته به دانشخاه

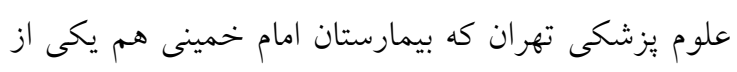


زاده و همكاران با نتيجه گيرى لزوم قرارگيرى برنامه ايمنى

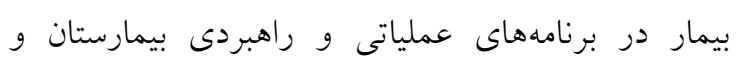

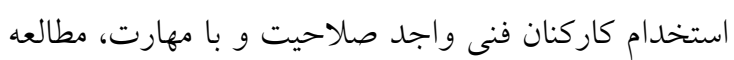

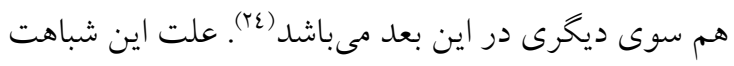

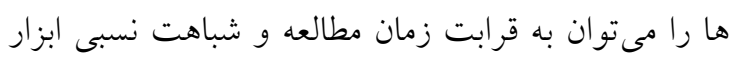
مورد استفاده و روتينهاى مديريت ايمنى در بيمارستانها

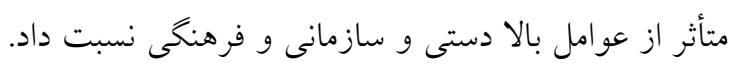

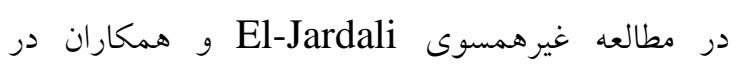

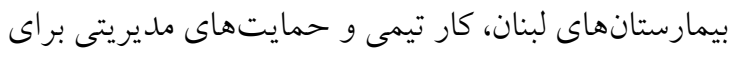

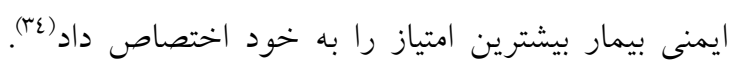
جون ميزان موفقيت در نيل به اهداف سازمانى در ارتباط مستقيم با نحوه عملكرد نيروهاى انسانى به ويزه مديران

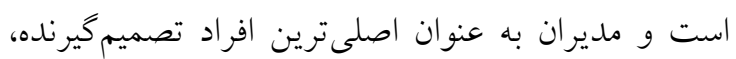
نقشى بهسزا و تعيين كننده در موفقيت و شكست سازمان

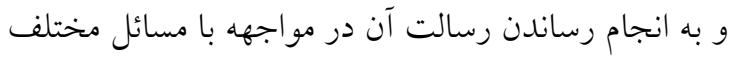

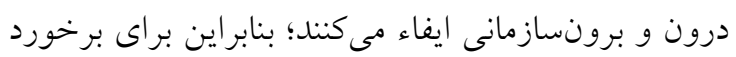

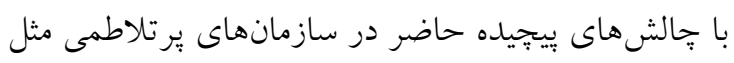

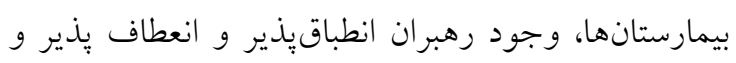

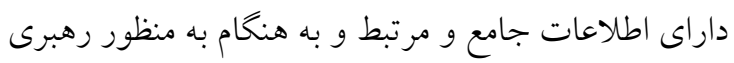
اثربخش، ضرورت دارد (ro).

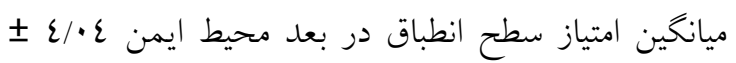

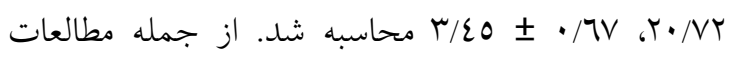

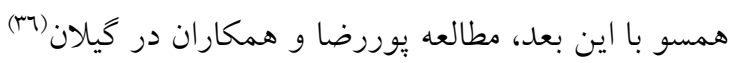
و مطالعه جبارى و همكاران مىباشد (rr). در مقابل نتايج مطالعه جهانگيرى و همكاران در شيراز و انطباق كامل با هـان استانداردهاى الزامى مورد بررسى آنها، غير همسو با يافته

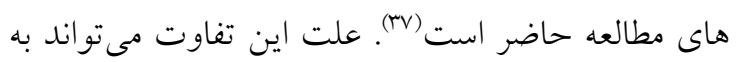
محيط يزوهش، مقاطع زمانى و تخصص متفاوت واحدهاى يزوهشى و نحوه جمع آورى دادهها مرتبط باشد. كمترين

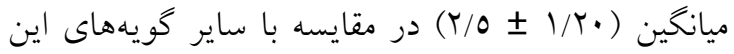
بعد به مؤلفهى "من احساس مىكنم مديريت بيمارستان

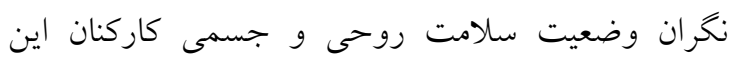

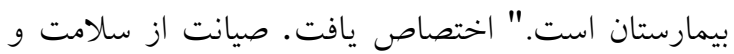

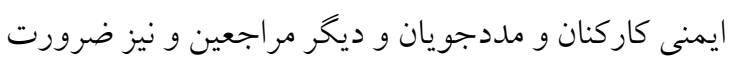

دست يابى به آن، به تحقيقات گستردهاى در خصوص روش هاى مختلف نيل به ايمنى بيمار و مداخله مؤثر براى ارتقاء بهاء

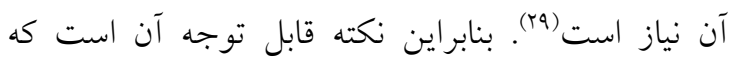
آموزش ايمنى بيمار يك وظيفه بيجتيده است كه بايد تمام

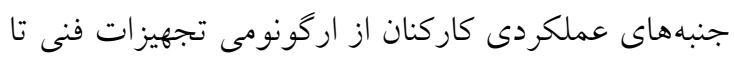

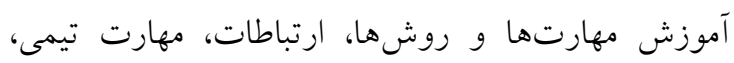

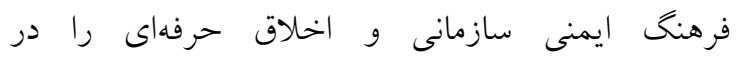
بر كيرد (rاr.r). مطالعات انجام شده، عامل كمبود آموزش و و مهارت ارائه دهندكان خدمات سلامت را از مهمترين دلايل رخداد خطاهاى خدمات سلامت كزارش مى كنند و تأثير

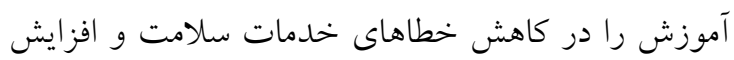
توانمندى حل مشكلات به ويزه در افراد بىتجربه و كم رهم

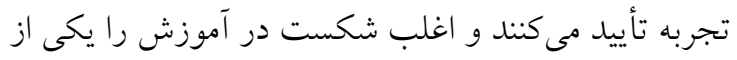
علل اصلى بروز حادثه و فقدان صلاحيت در كاركنان عنوان

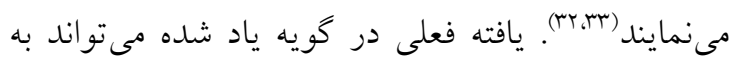

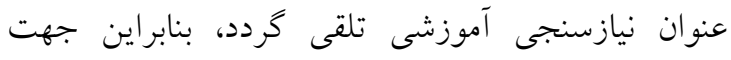

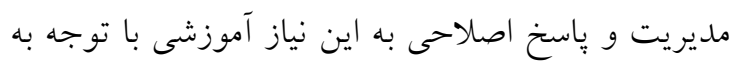

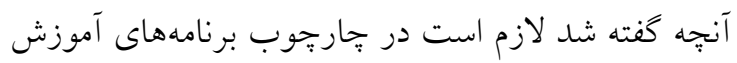

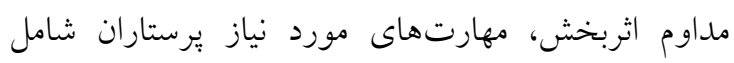

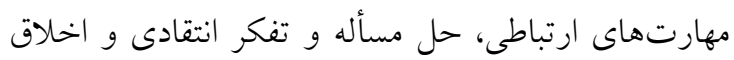

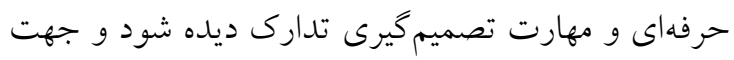

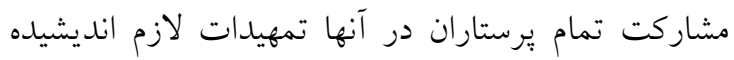

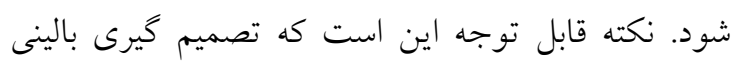

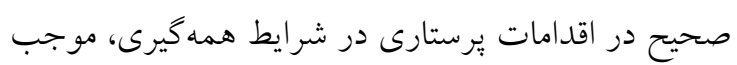

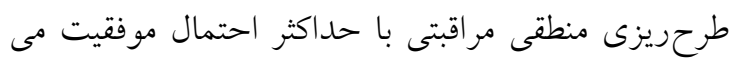
كر كمترين سطح انطباق مربوط به بعد حاكميت و رهبرى بود

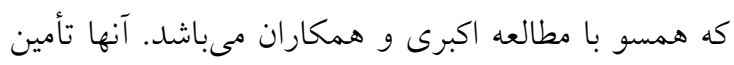

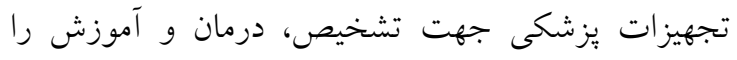

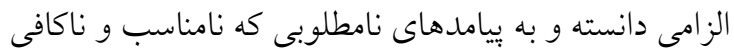
بودن تجهيزات به دنبال دارد اشاره نمودند و برنامهريزى

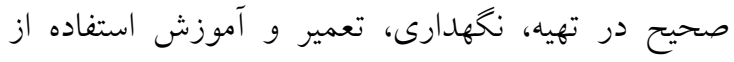
تجهيزات و طراحى سيستم مديريت اطلاعات در زمينه

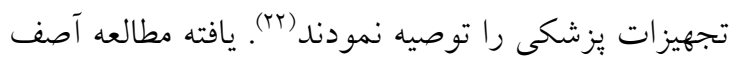


اعتباربخشى در بيمارستانها و مميزىهاى دورهاى و انجام اقدامات اصلاحى، روند رو به بهبود در بيمارستانها به به بهان

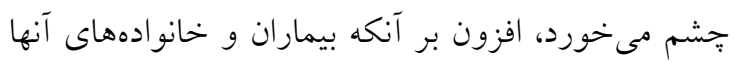

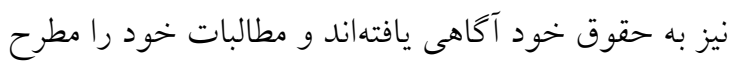

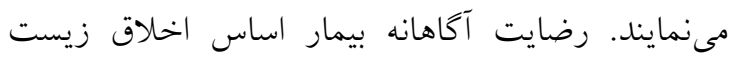

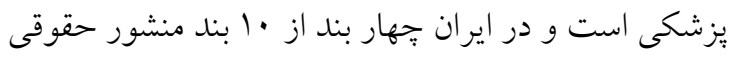

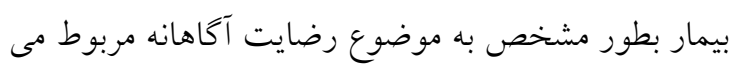

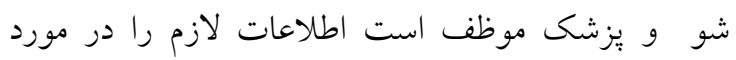
اقدامات تشخيصى درمانى بطور صريح، روشن و دقيق در

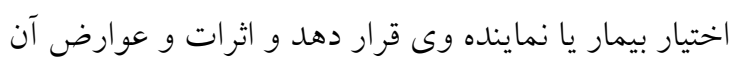

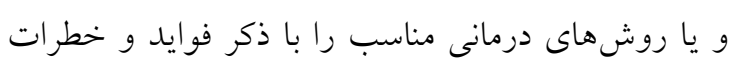

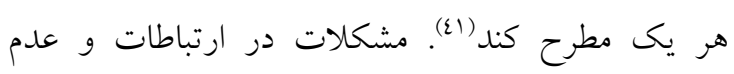

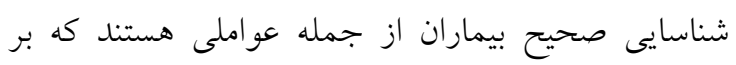

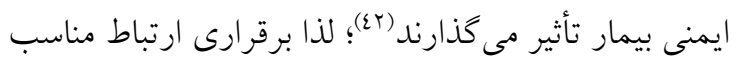

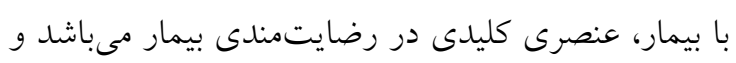

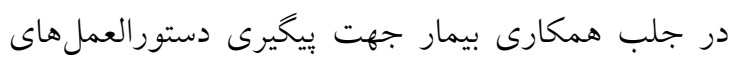
درمانى و مشاركت بيمار در فرآيند درمان و استقبال از طرح

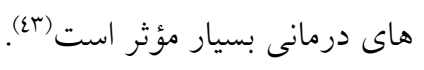

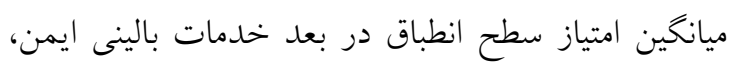

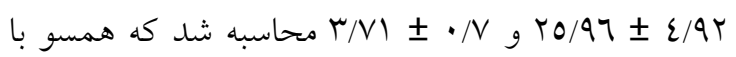
مطالعه اكبرى و همكاران(Tr) و غير همسو با مطالعه جبارى

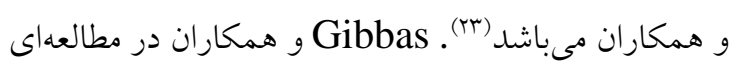

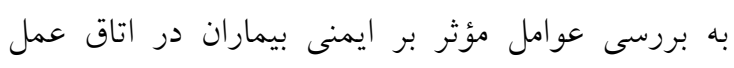

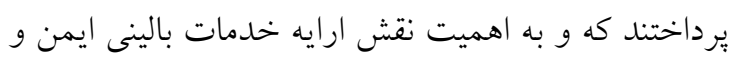

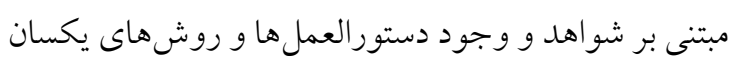
درمانى جهت كاهش خطاهاى رخ داده شده به منظور

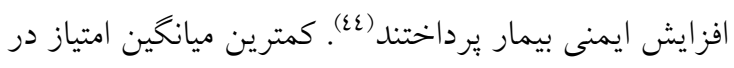

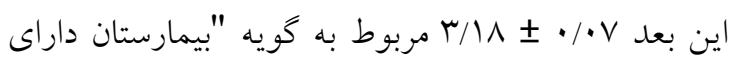

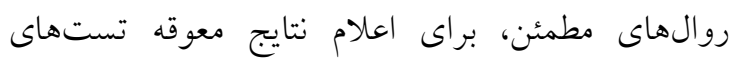

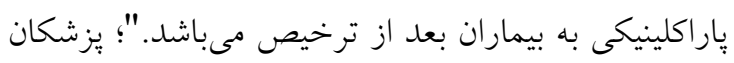

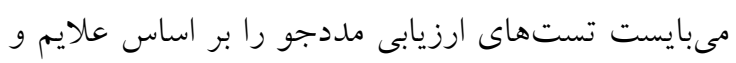

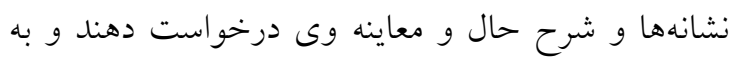
جاى استفاده از تستهاى روتين، از تستهاى انتخابى كه وس وله

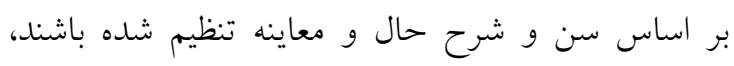

آمادكى بيمارستانها در موارد بروز اتفاقات، همه كيرىها و

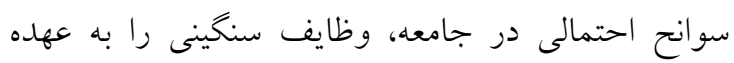

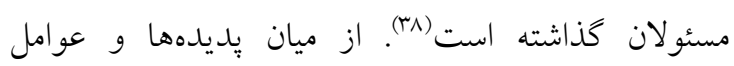
مختلف تأثير كذار بر بازده شغلى و سطح كارايى فرد،

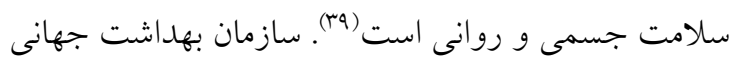

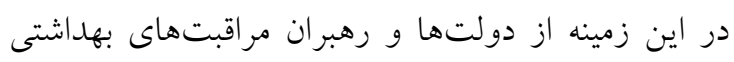

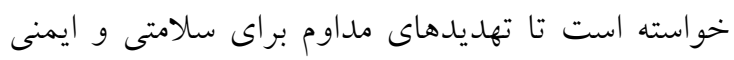
كاركنان سلامت و بيمار ان را برطرف كنند. صفا و همكاران

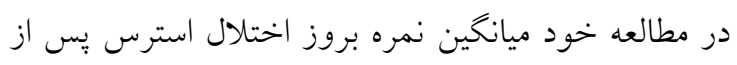

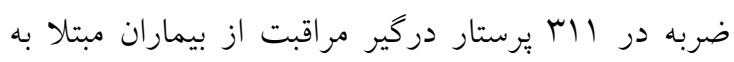

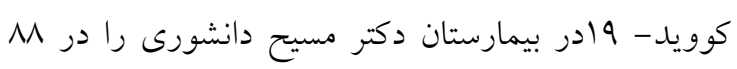

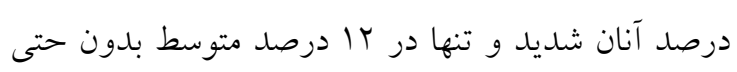
يكى مورد در گيرى خفيف، كزارش كردند كه اين يافته نشان ونان

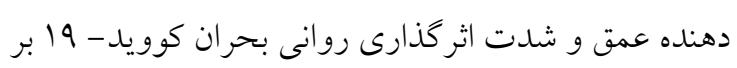

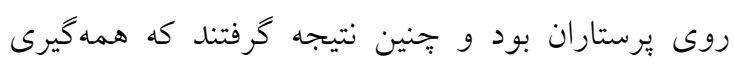

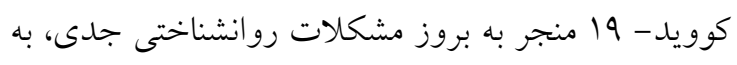
خصوص در كادر خط مقدم درمان مى شود و بايد به عنوان

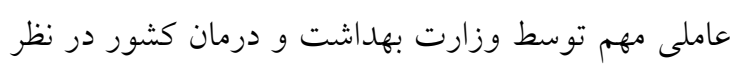

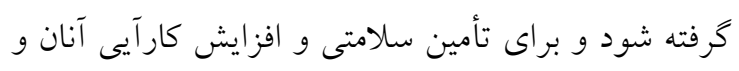

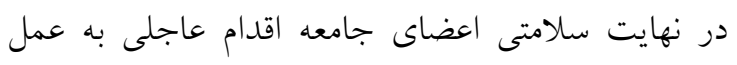

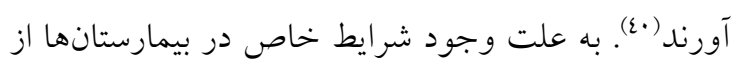

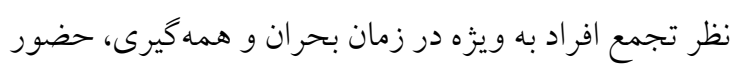

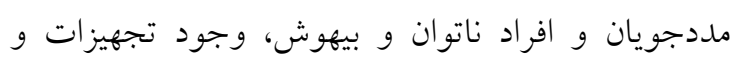

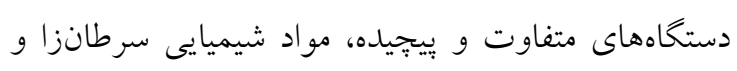

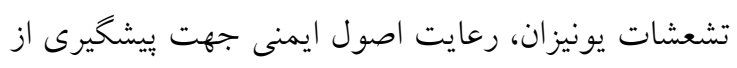

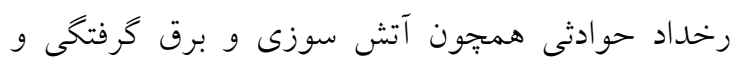

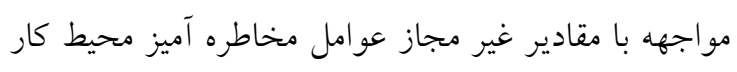

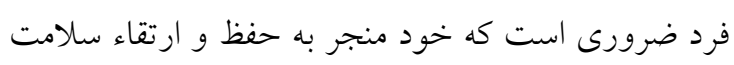
عمومى كاركنان به ويزّه بِرستاران مى شود (rv). ميانخين امتياز سطح انطباق در بعد جلب مشاركت و و تعامل

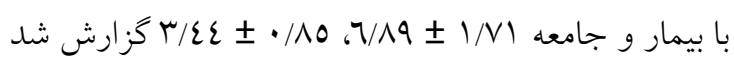
كه غيرهمسو با يافتهاى مطالعه اكبرى و همكاران(Tr)، جبارى و همكاران (Tr) است. علت اين ناهمسويى مى تو ماند

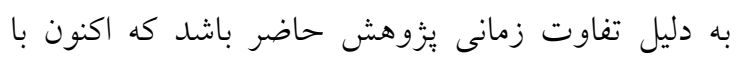


لينك يرسشنامه از طريق بيامرسان WhatsApp ارسال

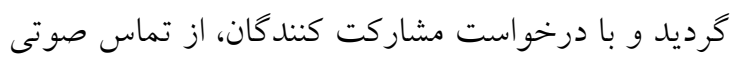
و تصويرى توجيهى در جهت مديريت محدوديتهاى برقرارى ارتباط مؤثر با مشاركت كنندكان استفاده شد.

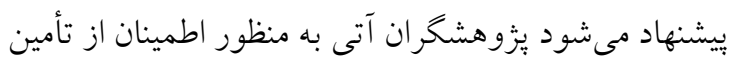
ايمنى بيمار و پايش كيفيت خدمات سلامت و بيمار محورى، مميزى قبل و بعد از مداخلهى بازخورد موارد غيرمنطبق استانداردهاى الزامى، اساسى و و بيشرفته

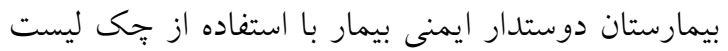

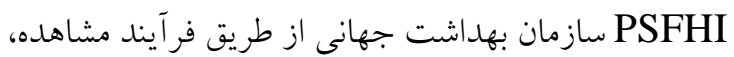
مصاحبه و بررسى مستندات را در مجتمع بيمارستانى امام خمينى به عمل آورند.

تعارض منافع: هيج گونه تعارض منافعى توسط نويسندگان بيان نشده است.

\section{تقدير و تشكر}

اين مطالعه بخشى از پيايان نامه كارشناسى ارشد رشته

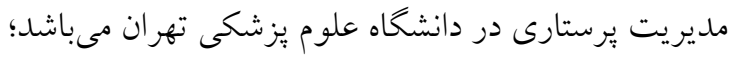
يزوهشكران مراتب سياس خود را از مجموعه معاونت

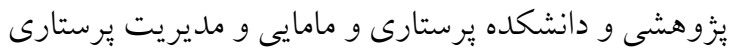

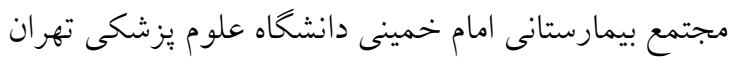
اعلام مى دارند. همجنين از تمامى يرستارانى كه با قرار دادن

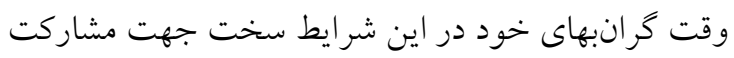

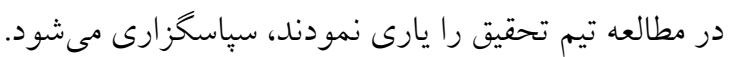

استفاده كنند تا تعداد تستهاى باراكلينيك غيرضرورى كه

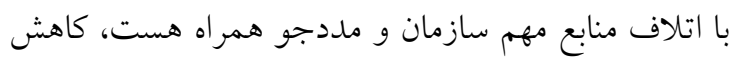
يابد. همجنين راه اندازى سامانه مشاهده اطلاعات بار اكلينك گام مؤثرى ديخرى در مديريت اين مهم مى باشند. بر اساس يافته هاى يُزوهش حاضر، در مجتمع بيمارستانى

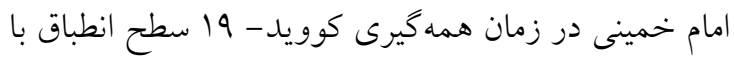

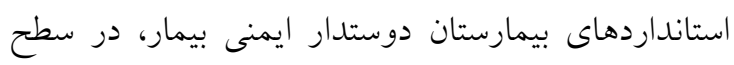

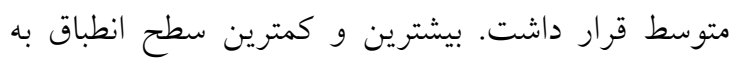

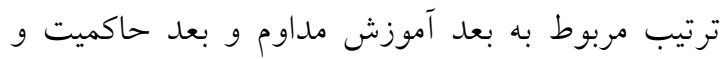
رهبرى از ابزار استانداردهاى بيمارستان دوستدار ايمنى

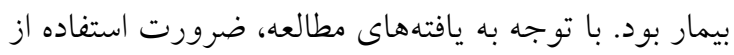

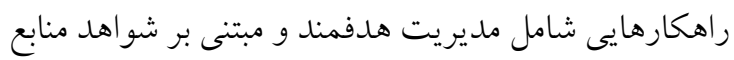
سازمانى، توجه به موانع تحقق ابعاد ايمنى، نهادينه كردن

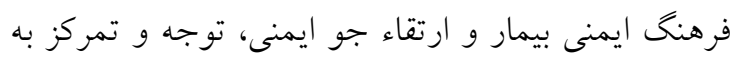

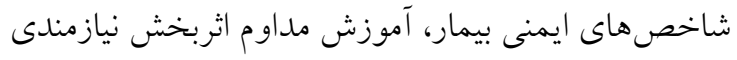
هاى آموزشى كاركنان در ارتقاء ايمنى ذينفعان در بيمارستان إندان ها بيش از ييش مشخص مىشود؛ تا بيمارستانها به انطباق داق

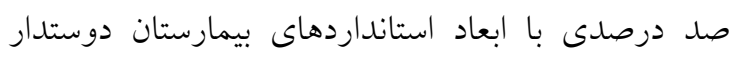

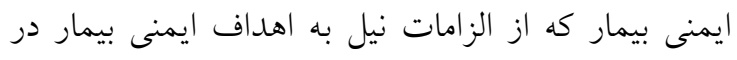

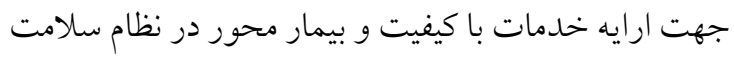

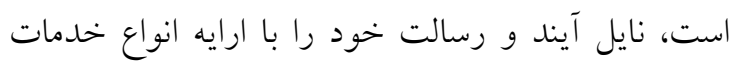
سلامت با كيفيت و ايمن، متناسب و منعطف، به موقع، رسادل عادلانه، اثربخش و مقرون به صرفه هويدا و وِايدار نمايند.

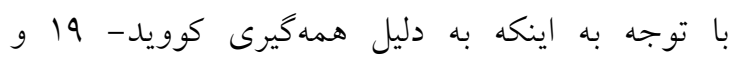

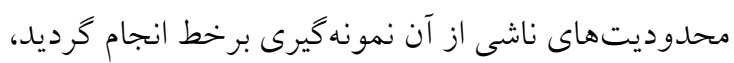
ييام توجيهى مكفى و متمركز بر موضوع مطالعه به همر اه

\section{References}

1. Brennan TA, Leape LL, Laird NM, Hebert L, Localio AR, Lawthers AG, Newhouse JP, Weiler PC, Hiatt $\mathrm{HH}$. Incidence of adverse events and negligence in hospitalized patients: results of the Harvard Medical Practice Study I. New Eng J Medic. 1991;324(6):370-6.

2. World Health Organization. Patient Safety: World Health Organization. 2015. 2018.

3. Psaty BM, Burke SP. Protecting the health of the public-Institute of Medicine recommendations on drug safety. New Eng J Medic. 2006;355(17):1753-5.

4. Nasiripour AA, Raeissi P, Ghaffari F, Maleki M, Jafari M. Ashkan NA, Pouran R, Farhad G, Mohhamadreza M, Mehrnush J. Designing A Medical Errors Control Model For Tehran University Of Medical Science Hospitals. Payavard Salamat. 2014;8(1):44-56. [Persian] 
5. World Health Organisation. patient safety. 2019 Available from: https://www.who.int/teams/integrated-health-services/patient-safety

6. Morshedizadeh M. Principles of hospital maintenance and safety. Tehran. 2010. p:15-30.

7. Pourtaghi GH, Hekmat M, Rafati Shaldehi H, Salem M. Hospital incidents' prevalence rate and its effective agents in the staff of a military hospital. Journal of Military Medicine. 2011;13(1):53-7. [Persian]

8. World Health Organization. Patient safety assessment manual, $2^{\text {nd }}$ ed.: EMRO Publications; 2016.

9. Christian CK, Gustafson ML, Roth EM, Sheridan TB, Gandhi TK, Dwyer K, Zinner MJ, Dierks MM. A prospective study of patient safety in the operating room. Surgery. 2006;139(2):159-73.

10. Adl J, Shokoohi Y, Kakooei H. Safety climate as an indicator to evaluate the performance of occupational health and safety management system. Journal of health. 2012;3(1):32-40. [Persian]

11. Mazhari Z, Adel A. Patient safety status in hospitals of Tehran-patient safety friendly hospitals standards: 2013. Journal of Payavard Salamat. 2015;8(5):379-89. [Persian]

12. World Health Organization. Home care for patients with suspected novel coronavirus ( $\mathrm{nCoV}$ ) infection presenting with mild symptoms and management of contacts: interim guidance, 20 January 2020.

13. Postel-Vinay S, Massard C, Soria JC. Coronavirus disease (COVID-19) outbreak and phase 1 trials: should we consider a specific patient management?. Europ J Cancer. 2020;137:235-9.

14. Al Thobaity A, Alshammari F. Nurses on the frontline against the COVID-19 pandemic: an integrative review. Dubai Medical Journal. 2020;3(3):87-92.

15. Sabet A, Jabari O, Alipour S, Sabet MR. Investigating the relationship between stress management and organizational commitment among nurses during Covid-19 pandemic, with the mediating role of communication skills training. Journal of Modern Medical Information Sciences. 2020;6(2):110. [Persian]

16. Mosalanezhad 1, Abiri S, Zeini jahromi M, Hatami N, Kalani N. Study of work-family conflict in nurses and physicians caring for patients with Covid 19: A cross-sectional descriptive study in 2020: An ethical challenge in the medical staff. Education and Ethics in Nursing. 2020;9(1):93101. [Persian]

17. Nathwani S, Rahman N. The 3 P's model enhancing patient safety during the COVID-19 pandemic. Oral Surgery. 2021 Feb 17.

18. Staines A, Amalberti R, Berwick DM, Braithwaite J, Lachman P, Vincent CA. COVID-19: patient safety and quality improvement skills to deploy during the surge. Int $J$ Qual Health Care. 2021;33(1):mzaa050.

19. Parvizi M. The impact of safety standards implementation on patient safety function at Shahid Faghihi Hospital in Shiraz .Shiraz: Islamic Azad University; 2018 ,Thesis. [Persian]

20. Smits M, Christiaans-Dingelhoff I, Wagner C, van der Wal G, Groenewegen PP. The psychometric properties of the'Hospital Survey on Patient Safety Culture'in Dutch hospitals. BMC health services research. 2008;8(1):1-9.

21. Sabouri G, Ghafghazi M, Zare M, Asadi M. Patient Safety Status in Selected Training Hospitals Affiliated to Mashhad University of Medical Sciences, Mashhad, Iran. J Patient Safety Quality Improvement. 2020;8(3):161-5. [Persian]

22. Habibzadeh H, Akbari F, Ghavami H, Moradi K. A Survey on the Establishment of Patient-Friendly Safety Standards in Urmia University of Medical Sciences. Journal of Urmia Nursing and Midwifery Faculty. 2019;17(7):525-34. [Persian]

23. Jabbari A, Raisi A, Rostami V. Patient safety status in selected training hospitals affiliated with Isfahan university of medical sciences. Health Information Management. 2015;12(1(41)):99-108. [Persian]

24. Asefzade S, Mehrabian F, Nikpey A, Kianmehr SH. Assessment of patient safety based on standards of patient safety friendly hospitals in education and treatment centers of Rasht City in 2013. [Persian]

25. Mohammad AR, Sari AA, Kor EM, Hosseini M, Rakhshan ST, Ezati M. Patient safety in Tehran university of medical sciences' general hospitals, Iran. Iranian journal of public health. 2013;42(3):306. [Persian]

26. Shahri S, Kebriaee A, Seyedi HR, Sarafraz Z. Patient safety climate in medical centers of Kashan. Journal of Health Promotion Management. 2012;1(1):62-72. [Persian] 
27. Kuriakose R, Aggarwal A, Sohi RK, Goel R, Rashmi NC, Gambhir RS. Patient safety in primary and outpatient health care. J Fam Medic Prim Care. 2020;9(1):7.

28. Zh N, Goudarzi Z, Keshmiri F, Pourreza A. Comparison of the education and research indicators of patient safety status between selected hospitals of Tehran University of Medical Sciences based on the WHO standards. Education Strategies in Medical Sciences. 2014;7(4):241-8. [Persian]

29. Gordon M, Findley R. Educational interventions to improve handover in health care: a systematic review. Med Educ. 2011;45(11):1081-9.

30. Manser T. Teamwork and patient safety in dynamic domains of healthcare: a review of the literature. Acta Anaesthesiologica Scandinavica. 2009;53(2):143-51.

31. Berenholtz S, Pronovost PJ. Barriers to translating evidence into practice. Current opinion in critical care. 2003;9(4):321-5.

32. Chopra V, Gesink BJ, DE JONG J, Bovill JG, Spierdijk J, Brand R. Does training on an anaesthesia simulator lead to improvement in performance?. Br J Anaesth. 1994;73(3):293-7.

33. Straight M. One strategy to reduce medication errors: the effect of an online continuing education module on nurses' use of the Lexi-Comp feature of the Pyxis MedStation 2000. CIN: Computers, Informatics, Nursing. 2008;26(1):23-30.

34. Dimassi H, El-Jardali F, Jaafar M, Jamal D, Hamdan R. The current state of patient safety culture in Lebanese hospitals. 2010.

35. Janati A, Dadgar E, Sadegh Tabrizi J, Asghari Jafarabadi M, GHolamzade Nikjoo R. Health system professionals, attitude towards necessary criteria for hospitals managers, performance assessment. Yafteh. 2012;14(3):91-101. [Persian]

36. Pourreza AG, Akbari HF, Khoda BV. Maintenance and Safety Management at Diagnostic Units of Gilan University of Medical Sciences'hospitals. Health Information Management Journal. 2006;3(2):93-102. [Persian]

37. Jahangiri M, Sorkhi F, Rasooli EZ, Izadi F. Compliance Study of Safe Environment Standards in Selected Hospitals of Shiraz University of Medical Sciences, Iran. Health System Reserch. 2016;12(1):27-31. [Persian]

38. Fathi M. Survey of status of security in the hospitals \& treatment health services of Kurdistan University of Medical Sciences in 2003. Scientific Journal of Kurdistan University of Medical Sciences. 2003;7(2):37-42. [Persian]

39. Kamali Dehkordi F, Maghsoudi S, Emami Sigaroudi A, Kazemnejad Leili E. Study of Predictive factors of public health based on job satisfaction in employees of Rasht city Health Service Centers. Journal of Holistic Nursing And Midwifery. 2015;25(4):110-7. [Persian]

40. Safa M, Esmailee S, GHasembroojerdi F, Hagizadeh F, myrabzadehardekani B. Incidence of posttraumatic stress disorder after COVID-19 among medical staff of masih Daneshvari hospital. Journal of Medical Council of Iran. 2020;38(1):27-33. [Persian]

41. Sheykh TA, Farzandipour M. Quality of informed consent process in inpatients undergoing surgery. Scientific Journal of Forensic Medicine. 2008;14(3):151-8. [Persian]

42. Christian CK, Gustafson ML, Roth EM, Sheridan TB, Gandhi TK, Dwyer K, Zinner MJ, Dierks MM. A prospective study of patient safety in the operating room. Surgery. 2006;139(2):159-73.

43. Asemani O. A review of the models of physician-patient relationship and its challenges. Iranian Journal of Medical Ethics and History of Medicine. 2012;5(4):36-50. [Persian]

44. Gibbs VC. Patient safety practices in the operating room: correct-site surgery and nothing left behind. Surgical Clinics. 2005;85(6):1307-19. 